\title{
RESÍDUOS DE PIRIMIFÓS-METIL EM GRÃOS DE TRIGO, MILHO E MILHO PIPOCA, EM ALGUNS DE SEUS \\ PRODUTOS PROCESSADOS E AÇÃO RESIDUAL \\ DESSE INSETICIDA SOBRE Sitophilus spp. (COLEOPTERA, CURCULIONIDAE)
}

\author{
Eduardo Sgarbiero
}

\begin{abstract}
Dissertação apresentada à Escola Superior de Agricultura "Luiz de Queiroz". Universidade de São Paulo, para obtenção do título de Mestre em Ciências, Área de Concentração:

Entomologia
\end{abstract}

PIRACICABA

Estado de São Paulo - Brasil

Novembro - 2001 


\title{
RESÍDUOS DE PIRIMIFÓS-METIL EM GRÃOS DE TRIGO, MILHO E MILHO PIPOCA, EM ALGUNS DE SEUS \\ PRODUTOS PROCESSADOS E AÇÃO RESIDUAL \\ DESSE INSETICIDA SOBRE Sitophilus spp. (COLEOPTERA, CURCULIONIDAE)
}

\author{
Eduardo Sgarbiero \\ Engenheiro Agrônomo
}

Orientador: Prof. Dr. GILBERTO CASADEI DE BAPTISTA

\begin{abstract}
Dissertação apresentada à Escola Superior de Agricultura “Luiz de Queiroz”. Universidade de São Paulo, para obtenção do título de Mestre em Ciências, Área de Concentração:

Entomologia
\end{abstract}

PIRACICABA

Estado de São Paulo - Brasil

Novembro - 2001 
Dados Internacionais de Catalogação na Publicação (CIP)

DIVISÃO DE BIBLIOTECA E DOCUMENTAÇÃO - ESALQ/USP

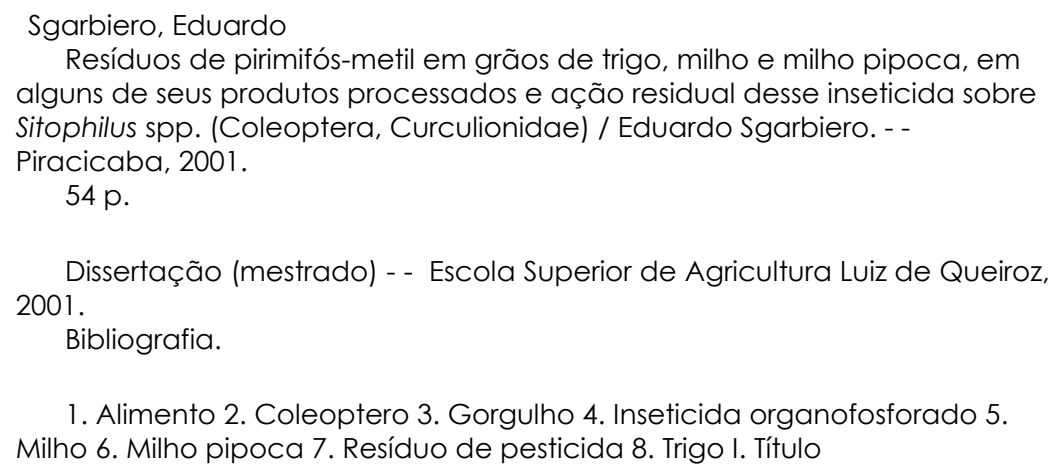

CDD 633.11

\section{"Permitida a cópia total ou parcial deste documento, desde que citada a fonte - O autor"}


A meus pais

PAULO e LUZIA (in memorian)

OFEREÇO

À minha esposa

VIRNA

Dedico 


\section{AGRADECIMENTOS}

Ao Prof. Dr. Gilberto Casadei de Baptista, pela orientação, apoio e grande compreensão durante todo o transcorrer deste trabalho.

Ao pessoal do Laboratório de Resíduos de Pesticidas, do Departamento de Entomologia, Fitopatologia e Zoologia Agrícola, ESALQ-USP, que colaboraram no desenvolvimento das pesquisas.

À Fundação de Amparo à Pesquisa do Estado de São Paulo - FAPESP, pela concessão da bolsa de estudos.

À Cargill Agrícola S.A, pela colaboração no processamento do trigo.

Ao Departamento de Produção Vegetal, ESALQ/USP e à Fecularia Santa Teresinha, pela colaboração no processamento do milho.

À todas aquelas pessoas que de alguma forma tenham colaborado para o bom desenvolvimento deste trabalho. 


\section{SUMÁRIO}

\begin{tabular}{|c|c|}
\hline & Página \\
\hline LISTA DE FIGURAS $\ldots \ldots \ldots \ldots \ldots$ & vii \\
\hline \begin{tabular}{|l} 
LISTA DE TABELAS $\ldots \ldots \ldots \ldots \ldots$ \\
$\ldots$
\end{tabular}$\ldots \ldots \ldots \ldots$ & viii \\
\hline $\operatorname{RESUMO} \ldots \ldots \ldots \ldots \ldots \ldots \ldots \ldots \ldots$ & $\mathrm{x}$ \\
\hline SUMMARY $\ldots \ldots \ldots \ldots \ldots \ldots \ldots$ & xii \\
\hline$\overline{1 \text { IINTRODUÇÃO } \ldots \ldots \ldots \ldots \ldots}$ & 1 \\
\hline 2 REVISÃO DE LITERATURA. . . . . . . . . . . . . . . . . . . . . & 3 \\
\hline 2.1 Controle de pragas dos grãos armazenados. . . . . . . . . . . . . . & 3 \\
\hline
\end{tabular}

................ 6

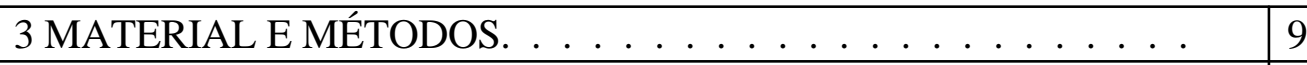

3.1 Limites de quantificação, porcentagens de recuperação e descrição do método de análilises de resíduos. . . . . . . . . . . . 9 3.1.1 Método de análises de resíduos de pirimifós-metil em grãos cereais e seus produtos processados. . . . . . . . . . . . . . . . . 9

\begin{tabular}{|c|c|}
\hline 3.1.1.1 Reagentes. . . . . . . . . . . . . . . . . . . . & 10 \\
\hline 3.1.1.2 Aparelhos, vidrarias e outros materiais. . . . . . . . . . . . & 10 \\
\hline 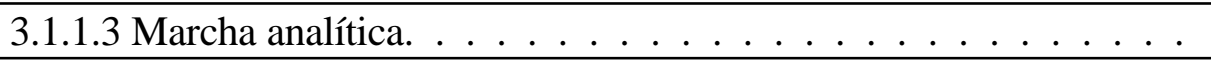 & 11 \\
\hline 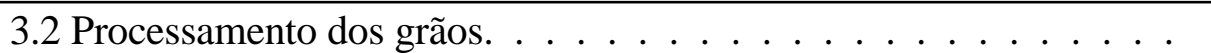 & 14 \\
\hline 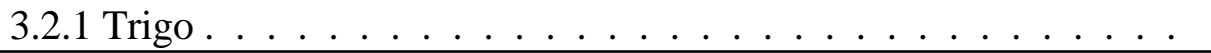 & 14 \\
\hline 3.2.2 Milho. & 14 \\
\hline 3.2 .3 Milho pipoca. $\ldots \ldots \ldots \ldots \ldots \ldots \ldots \ldots$ & 14 \\
\hline 3.3 Experimento de degradação e persistência. . . . . . . . . . . . . . . . & 15 \\
\hline 3.3.1 Tratamento dos grãos. . . . . . . . . . . . . & 15 \\
\hline 3.4 Atividade residual de pirimifós-metil aos adultos de Sitophilus spp. & 15 \\
\hline 3.4.1 Tratamento dos grãos. . . . . . . . . . . . . . . . . . . . . . . . & 15 \\
\hline 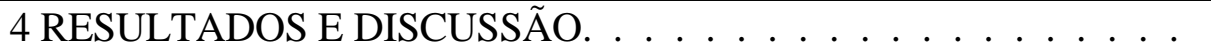 & 17 \\
\hline
\end{tabular}

17

4.2 Resíduos de pirimifós-metil em grãos de trigo e em seus produtos processados. . . .

4.3 Resíduos de pirimifós-metil em grãos de milho e em seus produtos processaddos. . . . .

\begin{tabular}{|l|l|}
\hline 4.4 Resíduos de pirimifós-metil em grãos de milho pipoca e pipoca. . . & 35 \\
\hline
\end{tabular} 


\begin{tabular}{|c|c|}
\hline 4.5 Efeito residual de pirimifós-metil aos adultos de Sitophilus spp.. . & 41 \\
\hline 5 CONCLUSÕES $\ldots \ldots \ldots \ldots$ & 49 \\
\hline REFERÊNCIAS BIBLIOGRÁFICAS . . . . . . . . . . & 50 \\
\hline
\end{tabular}




\section{LISTA DE FIGURAS}

\begin{tabular}{|c|c|}
\hline & Página \\
\hline & \\
\hline 1 Cromatogramas de extrato de grãos de trigo $\ldots \ldots \ldots \ldots \ldots \ldots \ldots$ & 20 \\
\hline 2 Cromatogramas de extrato de farelo de trigo. & 21 \\
\hline 3 Cromatogramas de extrato de farinha de trigo integral $\ldots \ldots \ldots \ldots \ldots$ & 22 \\
\hline 4 Cromatogramas de extrato de farinha branca. & 23 \\
\hline 5 Cromatogramas de extrato de pão $\ldots \ldots \ldots \ldots \ldots \ldots \ldots \ldots \ldots$ & 24 \\
\hline 6 Cromatogramas de extrato de grãos de milho $\ldots \ldots \ldots \ldots \ldots \ldots \ldots$ & 25 \\
\hline 7 Cromatogramas de extrato de farelo de milho $\ldots \ldots \ldots \ldots \ldots \ldots \ldots$ & 26 \\
\hline 8 Cromatogramas de extrato de grãos de milho canjicado (canjica) & 27 \\
\hline 9 Cromatogramas de extrato de farinha de milho $\ldots \ldots \ldots \ldots \ldots \ldots$ & 28 \\
\hline 10 Cromatogramas de extrato de milho pipoca $\ldots \ldots \ldots \ldots \ldots \ldots \ldots$ & 29 \\
\hline & \\
\hline
\end{tabular}




\begin{tabular}{|l|l|}
\hline 11 Cromatogramas de extrato de pipoca $\ldots \ldots \ldots \ldots \ldots \ldots \ldots \ldots \ldots \ldots$ & 30 \\
\hline & \\
\hline
\end{tabular}




\section{LISTA DE TABELAS}

Página

1 Porcentagem (\%) de recuperação de pirimifós-metil, pelo método de análise de resí́duos em amostras de grãos de trigo e seus produtos processados...... 18 \begin{tabular}{|l|l|}
\hline & \\
\hline 2 Porcentagem (\%) de recuperação de pirimifós-metil, pelo método de análise de resíduos em \\
\hline
\end{tabular} amostras de grãos de milho e seus produtos processados. .... 18 \begin{tabular}{|l|l|}
\hline & \\
\hline 3 Porcentagem (\%) de recuperação de pirimifós-metil, pelo método de análise de resíduos em \\
\hline
\end{tabular} amostras de grãos de milho pipoca e em pipoca. ........... 19 \begin{tabular}{|l|l|}
\hline & \\
\hline 4 Resíduos de pirimifós-metil em grãos de trigo e em seus produtos processados. . . . ...... \\
\hline
\end{tabular}

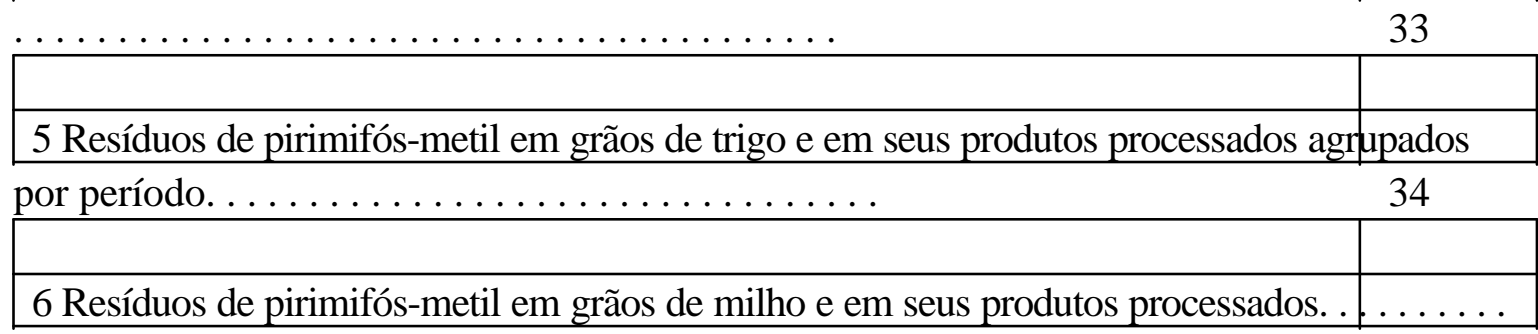

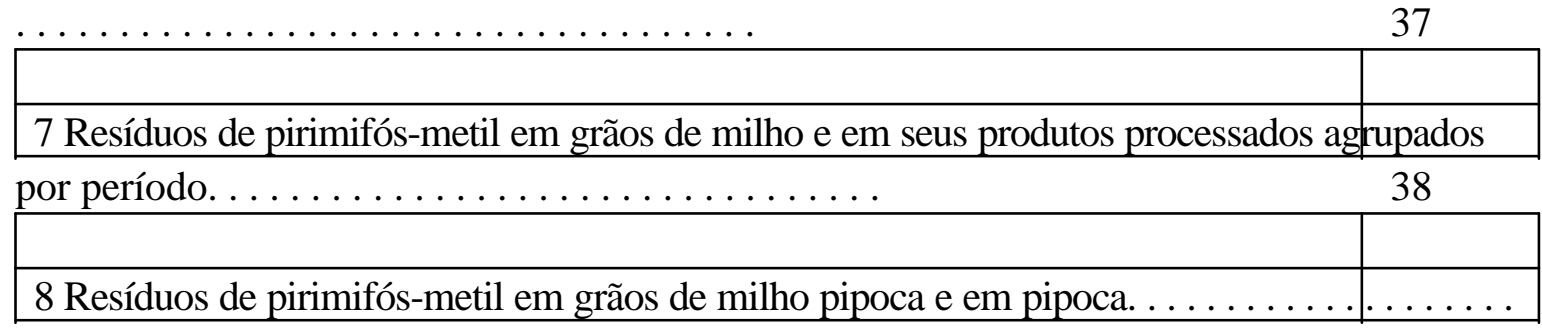
\begin{tabular}{|l|l|}
\hline & 40 \\
\hline 9 Resíduos de pirimifós-metil em grãos de milho pipoca e em pipoca agrupados por & \\
\hline
\end{tabular} ...................... 40 \begin{tabular}{|l|l|}
\hline 10 Número de adultos de Sitophilus spp. mortos por parcela, em amostras tratadas & (A) e \\
\hline
\end{tabular} testemunha (B) 15 dias após aplicação. ........... 42 \begin{tabular}{|l|l|}
\hline & \\
\hline 11 Número de adultos de Sitophilus spp. mortos por parcela, em amostras tratadas & (A) e \\
\hline
\end{tabular} 
testemunha (B) 30 dias após aplicação. .............. 42

\begin{tabular}{|l|l|}
\hline 12 Número de adultos de Sitophilus spp. mortos por parcela, em amostras tratadas & (A) e \\
\hline
\end{tabular}

testemunha (B) 60 dias após aplicação . . . . . . . . . . . 43

\begin{tabular}{|l|l|}
\hline 13 Número de adultos de Sitophilus spp. mortos por parcela, em amostras tratadas & (A) e \\
\hline
\end{tabular}

testemunha (B) 90 dias após aplicação. ............... 43

\begin{tabular}{|l|l|}
\hline & \\
\hline 14 Número de adultos de Sitophilus spp. mortos por parcela, em amostras tratadas & (A) e \\
\hline
\end{tabular}

testemunha (B) 120 dias após aplicação. .............. 44

\begin{tabular}{|l|l|}
\hline 15 Número de adultos de Sitophilus spp. mortos por parcela, em amostras tratadas & \\
\hline (A) e \\
\hline
\end{tabular}

testemunha (B) 150 dias após aplicação. .............. 44

\begin{tabular}{|l|l|}
\hline & \\
\hline 16 Número de adultos de Sitophilus spp. mortos por parcela, em amostras tratadas & (A) e \\
\hline
\end{tabular}

testemunha (B) 180 dias após aplicação. . . . . . . . . . 45

\begin{tabular}{|l|l|}
\hline 17 Número de adultos de Sitophilus spp. mortos por parcela, em amostras tratadas & \\
\hline (A) e
\end{tabular}

testemunha (B) 210 dias após aplicação. ............. 45

\begin{tabular}{|l|l|}
\hline 18 Número de adultos de Sitophilus spp. mortos por parcela, em amostras tratadas & \\
\hline (A) e \\
\hline
\end{tabular}

testemunha (B) 240 dias após aplicação. . . . . . . . . . . . 46

\begin{tabular}{|l|l|}
\hline & \\
\hline 19 Número de adultos de Sitophilus spp. mortos por parcela, em amostras tratadas & (A) e \\
\hline
\end{tabular}

testemunha (B) 270 dias após aplicação. .............. 46

\begin{tabular}{|l|l|}
\hline & \\
\hline 20 Número de adultos de Sitophilus spp. mortos por parcela, em amostras tratadas (A) e \\
\hline
\end{tabular}

testemunha (B) 300 dias após aplicação. . . . . . . . . . .... 47

\begin{tabular}{|l|l|}
\hline 21 Número de adultos de Sitophilus spp. mortos por parcela, em amostras tratadas & (A) e \\
\hline
\end{tabular}

testemunha (B) 330 dias após aplicação. . . ........... 47

\begin{tabular}{|l|l|}
\hline 22 Número de adultos de Sitophilus spp. mortos por parcela, em amostras tratadas & (A) e \\
\hline
\end{tabular}

testemunha (B) 360 dias após aplicação. . . . . . . . . . . . 48 


\title{
RESÍDUOS DE PIRIMIFÓS-METIL EM GRÃOS DE TRIGO, MILHO E MILHO PIPOCA, EM ALGUNS DE SEUS PRODUTOS PROCESSADOS E AÇÃO RESIDUAL DESSE INSETICIDA SOBRE
}

\author{
Sitophilus spp. (COLEOPTERA, CURCULIONIDAE)
}

Autor: EDUARDO SGARBIERO

Orientador: Prof. Dr. GILBERTO CASADEI DE BAPTISTA

\section{RESUMO}

Os objetivos do presente trabalho foram avaliar a ocorrência / persistência / degradação de resíduos do inseticida organofosforado pirimifós-metil em grãos de trigo, milho e milho pipoca e em alguns de seus produtos processados, bem como a ação residual desse inseticida sobre Sitophilus spp. (Coleoptera, Curculionidae). O tratamento dos grãos foi realizado de modo a se obter a concentração teórica de $12 \mathrm{mg} \cdot \mathrm{kg}^{-1}$ (ppm) de pirimifós-metil, tendo sido aplicados o equivalente a 5 litros de solução por tonelada de grãos. As amostras para estudos de resíduos foram tomadas aos zero, 15, 30, 60, 120 e 240 dias após o tratamento. O método analítico consta da extração dos resíduos com acetona, limpeza com 
partição acetonitrila/hexano seguida de coluna cromatográfica de sílica eluída com mistura de hexano+acetona $(9 / 1, \mathrm{v} / \mathrm{v})$. A determinação quantitativa foi feita por técnica de cromatografia em fase gasosa, usando-se cromatógrafo equipado com detector fotométrico de chama (GLC/FPD). Foram analisadas 264 amostras no total, sendo 72 de grãos cereais e 192 de seus produtos processados. Para os estudos de ação residual do inseticida sobre adultos de Sitophilus spp. os insetos foram submetidos a testes em exposição aos grãos tratados após 15 dias decorridos do tratamento, 30 dias após, e, subseqüentemente, em intervalos mensais até 12 meses. Os limites de quantificação dos resíduos pelo método de análise, para os diferentes substratos variaram de 0,05 a $0,1 \mathrm{mg} \cdot \mathrm{kg}^{-1}$. Os resíduos de pirimifós-metil não foram persistentes nos grãos nem em seus produtos processados, decrescendo de 4-8 vezes no período de amostragem. Eles foram maiores nos produtos processados ricos em óleos (farelo de trigo e de milho), menores nos grãos (estes semelhantes às farinhas integral e branca, e pipoca) e, ainda menores, no pão, farinha de milho e canjica. $\mathrm{O}$ inseticida pirimifós-metil mostrou-se bastante eficiente no controle de Sitophilus spp., no tratamento dos três tipos de grãos cereais durante todo o período de observação. 


\title{
RESIDUES OF PIRIMIPHOS-METIL ON WHEAT, CORN AND POPCORN GRAINS, IN SOME OF THEIR PROCESSED PRODUCTS AND RESIDUAL ACTION OF THE INSECTICIDE ON Sitophilus spp. (COLEOPTERA, CURCULIONIDAE)
}

\author{
Author: EDUARDO SGARBIERO
}

Adviser: Prof. Dr. GILBERTO CASADEI DE BAPTISTA

\section{SUMMARY}

The purposes of this study were to evaluate the occurence, persistence and degradation of pyrimiphos-methyl organophosphorus insecticide residues on wheat, corn and popcorn grains in and some of their processed products, as well the residual action of this insecticide for the control the Sitophilus spp. (Coleoptera, Curculionidae). Grain treatment was performed to obtain the theoretic concentration of $12 \mathrm{mg} \mathrm{Kg}^{-1}$ (ppm) of pyrimiphos-methyl, which was applied at the dosage of $5 \mathrm{~L}$ of solution/ton of the grain. Sampling was performed at $0,15,30,60,120$ and 240 days after the treatment. The samples were analyzed for residues of pyrimiphos-methyl using a residue method based on extraction with acetone, clean up by 
partition with acetonitrile/hexane followed by silica gel column chromatography eluted with a mixture of hexane + acetone (9:1) (v:v) solution. Residue determinations were done by the gas chromatography technique using a flame photometry detector (GLC/FPD). Total samples analyzed were 264, being 72 of cereal grains and 192 of processed products. The studies of residual action of the insecticide for the control of Sitophilus spp adults were conducted with adults and exposing the insects to treated grains 15 days after the application, 30 days, and subsequently at monthly intervals up to 12 months. The limits of quantitation of the analytical method for different substracts ranged between 0.05 to $0.1 \mathrm{mg} . \mathrm{kg}^{-1}$ (ppm). Pyrimiphos-methyl residues were not persistent on the grains and processed products. A decay of 4 to 8 times during the sampling period was observed. The residues found were higher in the processed products with high oil content (wheat and corn brans), lower on grains (similar to whole and white flours and popcorn) and even lower in bread, corn flour and "canjica". Pyrimiphos-methyl was very efficient for the control of Sitophilus spp on the three grain types during the entire period of observation. 


\section{INTRODUÇÃO}

Estima-se que $20 \%$ da produção nacional de grãos é perdida anualmente nos processos de colheita, de transporte e de armazenamento. Grande parte destas perdas deve-se a problemas fitossanitários, sendo somente as pragas de armazéns responsáveis por cerca de $10 \%$ da produção ou aproximadamente 7 milhões de toneladas de grãos.

Este problema assume maior significado considerando-se a grande importância dos grãos cereais na alimentação humana, o expressivo contingente de brasileiros vivendo em estado de desnutrição e, ainda, o fato de que certa parte dos investimentos públicos e privados, aplicados na produção de grãos, perde-se depois da colheita por efeito daqueles eventos.

Em razão dos problemas causados pelos insetos nos armazéns, tem-se usado principalmente substâncias químicas para controlar estas pragas e para preservação das colheitas; por outro lado, pode ocorrer a persistência destes inseticidas na forma de resíduos tóxicos nos grãos tratados, cujo consumo por parte do homem e dos animais, mesmo em quantidade sub-letais, representa risco potencial à saúde dos consumidores.

O controle oficial de resíduos de pesticidas em alimentos é geralmente baseado nos limites máximos de resíduos (LMR) ou tolerâncias e períodos de carência ou intervalos de segurança, estabelecidos caso a caso. Alguns estudos sobre a ocorrência de resíduos em grãos já são conhecidos entre nós. Entretanto, quase nada se sabe a respeito da ocorrência deles nos produtos processados e, em consequência, os riscos à saúde; de estudos estrangeiros, sabe-se que o processamento, em geral, reduz os resíduos nos produtos industrializados, mas em outros casos aumenta. 
Estudos sobre efeitos do armazenamento e algumas técnicas de processamento comerciais, em relação aos resíduos nos alimentos fazem parte da exigência para registro de pesticidas em muitos países. O JMPR, comitê da FAO/OMS, considera efeitos de processamento como parte de suas revisões de dados de resíduos de pesticidas (Holland et al., 1994).

Justifica-se o presente trabalho, pela necessidade inadiável de se obter dados, nas condições brasileiras, sobre influência do processamento nos níveis de resíduos de pesticidas em produtos agrícolas usados na alimentação humana e animal.

Este trabalho tem por objetivo estudar o comportamento do inseticida pirimifós-metil em grãos de trigo, milho e milho pipoca e em alguns de seus produtos processados, além de se avaliar o efeito deste inseticida sobre adultos de Sitophilus spp. 


\section{REVISÃO DE LITERATURA}

\subsection{Controle de pragas dos grãos armazenados}

A tecnologia utilizada para a preservação da boa qualidade dos grãos nos armazéns encontra nas pragas um dos principais problemas a serem controlados, para a manutenção da quantidade e qualidade desses produtos. Em face disto, inúmeras pesquisas com inseticidas tem sido desenvolvidas mundialmente neste campo.

LaHue (1975), com a aplicação de pirimifós-metil nas dosagens de 5, 10 e 20 ppm em grãos de trigo e milho, relata que o tratamento controlou totalmente os adultos de Rhyzopertha dominica (Fabr., 1792) (Coleoptera, Bostrichidae) infestados nos grãos 24 horas e um mês após. A proteção dos grãos se estendeu por 3 meses, a despeito do nascimento da geração $F_{1}$ nos tratamentos 5 ppm em milho e 5 e 10 ppm em trigo.

Segundo Cogburn (1976) a dosagem de 14 ppm de malation controlou $R$. dominica em 100; 97,1; 88,3 e 48,8\%, 1, 2, 3 e 6 meses, respectivamente, após o tratamento de grãos de arroz. Pirimifós-metil controlou o inseto em 100 e 95,1\%, 34,3 e 88,62; 48,8 e $90,4 \%$ e 21,2 e 56,7\% nas concentrações de 10 e 15 ppm, respectivamente 1, 2, 3 e 6 meses após o tratamento. A dosagem de 5 ppm foi ineficiente em todas as épocas de avaliação.

De acordo com Davies \& Desmarchelier (1981), a aplicação de 5,1 mg/kg de pirimifós-metil em grãos de trigo controlou eficientemente $S$. granarius (L., 1763), (Coleoptera, Curculionidae) e Tribolium confusum Du Val, 1868 (Coleoptera, Tenebrionidae) por 39 semanas, mas foi ineficiente contra a raça CRD 118 de $R$. dominica, resistente a 
malation.

Diversos organofosforados e piretróides sintéticos sinergizados foram utilizados por Bengston et al. (1983). Os autores obtiveram proteção por nove meses em grãos de trigo contra S. oryzae (L., 1763) e R. dominica. Os tratamentos usados foram deltametrina + butóxido de piperonila (PBO) $(2+8 \mathrm{ppm})$; fenitrotion + fenvalerato + PBO $(12+1+8 \mathrm{ppm})$; fenitrotion + fenotrina $+\mathrm{PBO}(12+2+8$ ppm $)$ e pirimifós-metil + permetrina $+\mathrm{PBO}(4+1+$ 8 ppm).

Rezende et al. (1984) trataram 10.000 toneladas de grãos de trigo em armazém da CEAGESP em Palmital-SP, com 0,35 ppm de deltametrina e infestaram amostras dos grãos tratados com Sitophilus spp., $R$. dominica e Tribolium spp., que foram acondicionadas em gaiolas. A mortalidade foi avaliada mensalmente até 180 dias após a aplicação, quando obtiveram controle de $80 \%$ para Sitophilus spp. e 95\% de $R$. dominica e Tribolium spp.

A mistura de deltametrina com PBO na dosagem de 0,5 ppm, estudada por Korunic \& Hamel-Koren (1985), foi considerada altamente eficiente contra os gorgulhos $S$. oryzae, S. granarius e R. dominica por 168 dias, excetuando-se para T. confusum. Pirimifósmetil a 4 ppm, protegeu os grãos armazenados no mesmo período contra os gorgulhos, sendo ineficiente contra $T$. confusum. Em relação a $R$. dominica foi eficiente até 28 dias, com decréscimo da eficiência aos 56 dias e inativo aos 84 dias.

Samson \& Parker (1989) testaram a eficiência de nove inseticidas utilizados para controle de pragas de milho armazenado. A ordem de eficiência de fosforados em ordem decrescente, contra T. castaneum Herbst, 1795 e $S$. oryzae foi: clorpirifós-metil > pirimifósmetil > metacrifós > fenitrotion. Em relação a $R$. dominica, a dos inseticidas piretróides foi: deltametrina $>$ fenvalerato $>$ permetrina $=$ bioresmetrina $>$ D-fenotrina. $R$. dominica foi eficientemente controlada com deltametrina $(0,04 \mathrm{ppm})$, fenvalerato $(0,25 \mathrm{ppm})$ e permetrina (0,5 a 1,0 ppm) durante nove meses, sendo, ainda, exigidas altas dosagens de bioresmetrina e D-fenotrina para o controle do inseto.

O controle de duas importantes pragas do trigo armazenado, $S$. oryzae e $R$. dominica, foi estudado por Campos et al. (1991). Os seguintes tratamentos foram aplicados: deltametrina (0,35 e 0,70 ppm); malation (20 ppm); pirimifós-metil (4 e 8 ppm); fenitrotion (5 e $10 \mathrm{ppm})$ e as misturas de deltametrina e malation (0,35 e 20 ppm); deltametrina e pirimifós- 
metil ( 0,35 e 4,0 ppm); deltametrina e fenitrotion ( 0,35 e 5,0 ppm) e testemunha. Decorridos 180 dias da aplicação, concluíram que os fosforados foram eficientes no controle de $S$. oryzae e o piretróide no de $R$. dominica.

Schroter et al. (1991) compararam as dosagens de 0,25; 0,50; 0,75 e 1,0 ppm de deltametrina com 8,0 ppm de pirimifós-metil, no controle de $R$. dominica em grãos de trigo infestados uma semana antes da aplicação, quando foram retirados os adultos. Deltametrina foi mais eficiente até 390 dias com mortalidades superiores a 96,2\%. Pirimifós-metil permitiu sobrevivência da progênie da praga com 0,8 a 1,8 inseto por parcela de $40 \mathrm{~cm}^{3}$ de grãos aos 60 e 90 dias após o tratamento, respectivamente.

Bitran et al. (1991) avaliaram a eficiência de inseticidas organofosforados e piretróides sobre algumas pragas de produtos armazenados. Pirimifós-metil foi o melhor inseticida para proteção de grãos de milho contra S. zeamais, seguido de cipermetrina e fenitrotion, sendo ainda o primeiro mais eficiente no controle de $S$. oryzae em trigo e arroz, enquanto deltametrina, cipermetrina e fenitrotion mostraram algum efeito residual sobre esta praga. Contudo, deltametrina foi o melhor tratamento contra $R$. dominica em trigo.

Santos \& Waquil (1993) testaram a eficiência de deltametrina nas concentrações de 0,5; 1,0 e 2,0 ppm; fenitrotion e pirimifós-metil, ambos nas concentrações de 12, 16 e 32 ppm, no controle de $S$. oryzae, S. zeamais e $R$. dominica em grãos de arroz armazenado. Os resultados obtidos mostraram que $R$. dominica somente pôde ser controlada quando esteve presente o piretróide nos tratamentos, o mesmo ocorrendo com os gorgulhos quando os fosforados estiveram presentes. Como geralmente estas espécies ocorrem juntas em arroz armazenado, os pesquisadores recomendam que se utilize misturas destes dois grupos de inseticidas.

Gabriel et al. (1989) desenvolveram um bio-ensaio de concentração de inseticidas em grãos de trigo utilizando $R$. dominica. Foram feitas regressões lineares para se medir a toxicidade de malation, fenitrotion, pirimifós-metil e deltametrina. O bio-ensaio mostrou resultados semelhantes aos encontrados nas análises por cromatografia para os resíduos, exceto no caso do malation. 


\subsection{Resíduos de inseticidas em grãos armazenados e em seus produtos processados}

Na utilização de produtos químicos em mistura com os grãos, visando sua proteção contra o ataque de pragas, deve-se considerar as normas relacionadas com os resíduos, que definem os LMR's e os intervalos de segurança variáveis para consumo, de acordo com o inseticida empregado e o tipo de grão ou produto em questão.

De acordo com LaHue (1975), depósitos iniciais de pirimifós-metil de 5, 10 e 20 ppm em grãos de milho, resultaram níveis residuais de 6,9 e 2,1 ppm, 24 horas e 3 meses após o tratamento, respectivamente, para a dosagem de $5 \mathrm{ppm} ; 8,0$ e 4,7 ppm para a dosagem de 10 ppm e 10,8 e 10,0 ppm para a dosagem de 20 ppm, para os mesmos períodos de armazenamento.

Mensah et al. (1979) relataram que da aplicação de 4 e 6 ppm de pirimifós-metil em grãos de trigo, com 12 e 16\% de umidade, resíduos de 3,29; 2,98 e 2,54 ppm foram obtidos para a menor dosagem e 4,93, 4,54 e 3,66 ppm para a maior, em grãos com 12\% de umnidade, 1, 3 e 6 meses após o tratamento, respectivamente. Para grãos tratados com 16\% de umidade, resíduos de 3,24; 3,04 e 2,26 ppm foram obtidos para a menor dosagem e 4,92; 4,44 e 3,86 ppm para a maior, nos mesmos períodos após o tratamento.

Para o controle de pragas de sorgo armazenado, resistentes a malation, Bengston et al. (1984) utilizaram deltametrina + PBO (2 e 8 ppm) e pirimifós-metil + permetrina + PBO (6, 1 e 8 ppm), respectivamente. Os resíduos encontrados nos grãos amostrados $0 ; 17$ e 26 semanas após o tratamento foram 1,8; 1,5 e 1,0 ppm de deltametrina, respectivamente, enquanto que estes apresentaram níveis de 6,5; 4,2 e 3,5 ppm de pirimifós-metil nos mesmos períodos.

Sowunmi \& Fetuga (1985) trataram grãos de milho com 20 ppm de pirimifós-metil que foram armazenados a granel, em silos, Os autores relataram que 70\% do depósito inicial do inseticida foi degradado em 5 meses de armazenamento. Por outro lado, grãos de milho tratados com 10 ppm do mesmo inseticida e armazenados em sacos de juta e polietileno, tiveram meia-vida de degradação dos resíduos somente 12 meses após a aplicação.

A recomendação para o tratamento de grãos de trigo e cevada com pirimifós-metil, 
segundo Le Patourel (1992) é de 4 ppm no Reino Unido. O autor aplicou dosagens calculadas de 3,9 e 3,7 ppm do inseticida nos grãos, respectivamente, obtendo em trigo, no período de 0 a 240 dias, variação residual de 1,44 a 1,33 ppm. Em grãos de cevada, no período de 0 a 210 dias, obteve-se a variação de 4,03 a 3,62 ppm. Concluiu-se que não houve variação residual de pirimifós-metil durante os períodos estudados, mas que houve grande variação nos pontos amostrados, revelando grande irregularidade no método de aplicação.

No Brasil, Alleoni (1995) tendo tratado milho com pirimifós-metil (6 e 12 ppm), malation (20 e 40 ppm) e deltametrina (0,5 e 1 ppm) e analisando resíduos desses inseticidas nos grãos mensalmente, durante 180 dias, relatou meias-vida de resíduos de 93, 109 e 107 dias, respectivamente.

A viabilidade do uso de fentoato na concentração de 5 ppm para tratamento de grãos de trigo, foi estudada por Bazzi et al. (1972). Os autores observaram que o inseticida afetou a qualidade dos produtos obtidos por moagem além dos pães derivados desses grãos. A concentração do ingrediente ativo restante na farinha, pão, farelo fino e farelo, cinco meses após o tratamento, foi de 0,$4 ; 0,1 ; 8,3$ e 12,2 ppm, respectivamente.

Mensah et al. (1979), em estudos conduzidos com malation, bromofós, iodofenfós e pirimifós-metil nas concentrações de 8 e 12 ppm em grãos de trigo, observaram altas concentrações de resíduos no farelo e baixos níveis na farinha.

Bengston et al. (1980) compararam os resíduos de diversos produtos em trigo e obtiveram a seguinte ordem decrescente de persistência: pirimifós-metil > fenotrina > carbaril e fenitrotion. Durante o processamento para pão branco, os resíduos foram reduzidos em $98 \%$ para carbaril, $48 \%$ para fenotrina, $98 \%$ para fenitrotion e $85 \%$ para pirimifós-metil. Ainda, Bengston et al. (1983) determinaram que os resíduos de deltametrina, fenvalerato, permetrina e fenotrina são altamente persistentes em trigo armazenado. Durante a moagem, eles tendem a se acumular no farelo e muito pouco na farinha branca, não se observando redução dos níveis após a operação de cozimento.

Papadopoulou \& Tomazou et al. (1991) aplicaram permetrina (2 e 8 ppm) e permetrina + PBO $(2+2$ ppm) em grãos de trigo e em suas frações moídas. Após 35 dias de armazenamento, 75-80\% dos resíduos foram encontrados no farelo; 427 dias após eles não foram encontrados na farinha dos grãos tratados com 2ppm. 
A redução dos resíduos de pirimifós-metil, durante o armazenamento de trigo tratado na dosagem de 4 ppm do inseticida, por 1, 3 e 6 meses foi estudada por Brown et al. (1991). As amostras foram submetidas à uma limpeza por atrito para remover parte de suas cascas. Esta operação removeu 17-28\% mais resíduos do inseticida do que a limpeza convencional. Uma grande redução de resíduos ocorreu quando o pesticida foi aplicado na formulação de pó seco em relação à aplicação na de concentrado emulsionável. Houve maior dificuldade na remoção dos resíduos por este processo, com o aumento do tempo de armazenamento.

Grãos de trigo tratados com pirimifós-metil e suas frações moídas tiveram seus resíduos analisados por Pucceti et al. (1993). Os resultados indicam que o processo de lavagem antes da moagem removeu boa parte dos resíduos do inseticida; a meia vida deles em grãos foi de 6 meses.

Maciel et al. (1993) trataram grãos de trigo com 7,5 e 15 ppm de fenitrotion dos quais foi obtida posteriormente a farinha. Os tratamentos apresentaram resíduos na farinha de 2,1 e 3,0 ppm, respectivamente, 1 dia após o tratamento e de 0,15 e 0,39 ppm 90 dias após. 


\section{MATERIAL E MÉTODOS}

\subsection{Limites de quantificação, porcentagens de recuperação e descrição do método de análises de resíduos}

Para o estudo dos limites de quantificação e porcentagens de recuperação dos resíduos do inseticida em grãos e seus produtos processados, amostras foram fortificadas, de modo a se obter concentrações nos níveis de 10,0;1,0;0,1; 0,05; 0,02 e 0,01 mg.kg-1 (ppm), em duplicata, e preparadas para análises da mesma maneira às amostras destinadas aos estudos de resíduos nos grãos e em seus produtos processados (estudos de degradação e de persistência). Foram, assim, realizadas análises em 132 amostras fortificadas a saber: 11 substratos x 6 níveis x 2 repetições.

\subsubsection{Método de análises de resíduos de pirimifós-metil em grãos cereais e seus produtos processados}

O método de análise consta da extração dos resíduos de pirimifós-metil das amostras com acetona. A limpeza do extrato é feita em partição de hexano e acetonitrila e coluna cromatográfica de sílica-gel, sendo a eluição procedida com uma mistura de hexano + acetona; segue-se determinação quantitativa em cromatógrafo de gás equipado com detector fotométrico de chama (GLC/FPD). 


\subsubsection{Reagentes}

- acetona - AR, Malinckrodt, 2440;

- acetonitrila - PA; Merck, 17;

- hexano - AR, Malinckrodt, 5189;

- $\quad$ sílica gel - Merck, 7734;

- padrão analítico de pirimifós-metil.

\subsubsection{Aparelhos, Vidrarias e Outros Materiais}

- cromatógrafo a gás, HP, modelo 6890 , equipado com detector fotométrico de chama (FPD), portando filtro específico para fósforo de $526 \mathrm{~nm}$;

- Integrador Varian, modelo 4400;

- coluna cromatográfica megabore HP 5, com 5 m comprimento, diâmetro de 0,53mm e $1,5 \mu \mathrm{m}$ de espessura do filme;

- manifold, vidro, com seis bicos;

- chapa aquecedora;

- moinho de laboratório, Marte, modelo MA-020;

- mesa agitadora orbital, Marconi, modelo FVR C9S;

- balança analítica, Mettler, modelo H10;

- balança analítica, Sartorius, modelo Basic;

- microseringa - $10 \mu \mathrm{l}$, Hamilton;

- centrífuga Revan, modelo ciclo C-1;

- frascos com tampa rosqueável de 100 mL, Duran-Schott;

- tubos de centrífuga de $50 \mathrm{~mL}$, polipropileno, Corning 25330-50;

- tubos de centrífuga graduados de 15 mL, Corning Pyrex 8080;

- seringas hipodérmicas plásticas de $10 \mathrm{~mL}, \mathrm{~B}-\mathrm{D}$;

- provetas graduadas de 10, 25 e $250 \mathrm{~mL}$; 
- pipetas graduadas de 1,5 e $10 \mathrm{~mL}$;

- pipetas volumétricas de $25 \mathrm{~mL}$;

- EM-dispenser, Hirschmann 5-30 mL;

- beacker de $100 \mathrm{~mL}$, Corning Pyrex 1000;

- ultra-som, Mini-som;

- espátulas;

- vidro âmbar de $30 \mathrm{~mL}$, com tampa rosqueável;

- vidro transparente de $15 \mathrm{~mL}$, com tampa rosqueável.

\subsubsection{Marcha Analítica}

\section{A. Extração}

A.1. Pesar $10 \mathrm{~g}$ da amostra homogeneizada (5 g para pipoca), colocar em tubo DuranSchott, , juntar $50 \mathrm{~mL}$ de acetona e deixar em agitação na mesa agitadora durante 15 minutos a 360 rpm (fortificar no caso de estudos de recuperação, com adição de 1 $\mathrm{mL}$ de padrões, previamente preparados, em concentrações necessárias para se obterem os níveis de fortificação anteriormente citados).

A.2. Centrifugar a $2.500 \mathrm{rpm}$ por 5 minutos para melhor separação da fase líquida e materiais em suspensão.

A.3. Transferir uma alíquota de $5 \mathrm{~mL}$ do sobrenadante para tubo de centrífuga de $50 \mathrm{~mL}$.

A.4. Evaporar o solvente contido nos tubos de centrífuga com auxílio de ar movente em manifold e banho-maria à $45-50^{\circ} \mathrm{C}$.

\section{B. Limpeza}

B.1. Adicionar aos tubos de centrífuga $8 \mathrm{~mL}$ de hexano saturado de acetonitrila e $25 \mathrm{~mL}$ de acetonitrila saturado de hexano e agitar muito bem por um minuto.

B.2. Centrifugar a 2.500 rpm durante 5 minutos.

B.3. Tomar toda a fase inferior (acetonitrila) em tubos de centrifuga de $50 \mathrm{~mL}$. 
B.4. Evaporar completamente o conteúdo dos tubos com auxílio de ar movente em manifold e banho-maria a $60-65^{\circ} \mathrm{C}$.

B.5. Ressuspender os extratos em $5 \mathrm{~mL}$ de hexano.

B.6. Preparar coluna cromatográfica a partir de seringa hipodérmica de $10 \mathrm{~mL}$ da seguinte maneira: retirar o êmbolo, colocar algodão ao fundo, adicionar $1 \mathrm{~g}$ de sílica-gel e por ultimo uma camada de algodão. Recolocar o êmbolo e comprimir o enchimento da seringa com força. Retirar de volta o êmbolo.

B.7. Pré-umidecer a coluna com $5 \mathrm{~mL}$ de hexano.

B.8. Transferir o extrato contido em B.5 para a coluna e descartar todo o eluado, lavar o tubo com mais $5 \mathrm{~mL}$ de hexano, descartando, igualmente, o eluado.

B.9. Eluir a coluna com $15 \mathrm{~mL}$ da mistura de hexano + acetona $(9 / 1, \mathrm{v} / \mathrm{v})$, recolhendo o eluado em tubos de centrífuga de $15 \mathrm{~mL}$.

B.10. Evaporar até a secura em manifold e banho-maria, à $45-50^{\circ} \mathrm{C}$, com auxílio de ar movente.

C. Determinação quantitativa

C.1. Ressuspender os resíduos provenientes de B.10 com 10-12 mL de acetona; e deixar no ultra-som por 1 minuto; concentrar de volta para $1 \mathrm{~mL}$, na marca, com auxílio de ar movente em banho-maria a $45-50{ }^{\circ} \mathrm{C}$, em manifold.

C.2. Injetar alíquotas no cromatógrafo;

C.3. Condições de operação do cromatógrafo:

Temperaturas:

- $\quad$ coluna $=190{ }^{\circ} \mathrm{C}$

- $\quad$ injetor $=250^{\circ} \mathrm{C}$

- $\quad$ detector $=250^{\circ} \mathrm{C}$

Fluxos de $\mathrm{N}_{2}$ :

- $\quad$ coluna $=10 \mathrm{~mL} / \mathrm{min}$

- make-up = $50 \mathrm{~mL} / \mathrm{min}$

Fluxo de ar $=110 \mathrm{~mL} / \mathrm{min}$ 
Fluxo de $\mathrm{H}_{2}=150 \mathrm{~mL} / \mathrm{min}$

Range: 5

Tempo de retenção $=2$ minutos.

C.4. Cálculo das porcentagens de recuperação

As porcentagens de recuperação são calculadas pela fórmula:

massa do inseticida em ng (calculada dos cromatrogramas)

$\%$ rec. $=$

x100

massa teórica injetada do inseticida em ng

C. 5. Cálculo dos resíduos

Os resíduos são calculados por comparação direta com o padrão (padronização externa), baseadas nas massas do padrão analítico e das amostras pela fórmula:

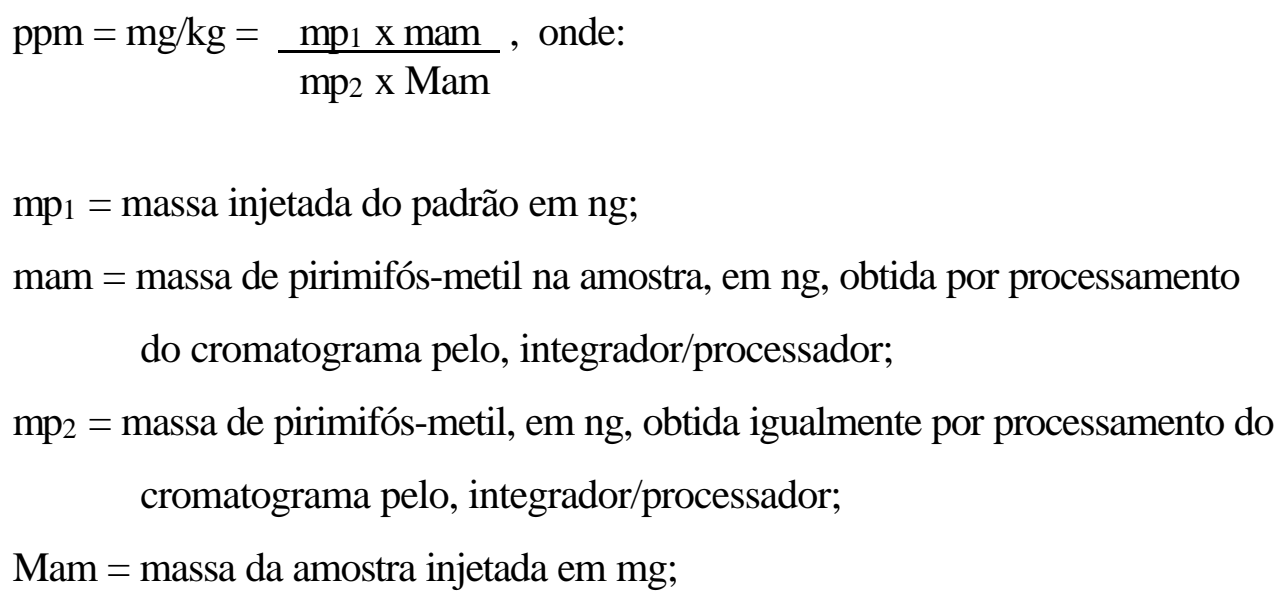




\subsection{Processamento dos grãos}

\subsubsection{Trigo}

O processamento do trigo foi realizado no Laboratório de Controle de Qualidade da Cargill Alimentos, localizado no Município de Tatuí-SP. Às amostras foi adicionada água suficiente para elevar a umidade dos grãos à 15,5\%, sendo depois processadas em moinho da marca Chopin, modelo CD 1, o qual fornecia a farinha branca e o farelo, sendo a farinha integral obtida a partir da mistura desses dois componentes na proporção de 85/15, respectivamente. O pão foi feito de modo caseiro, utilizando-se farinha branca, leite, água, fermento, óleo de soja, ovo, sal e açúcar, sendo a massa assada em forno comum por um período de aproximadamente 50 minutos.

\subsubsection{Milho}

As amostras de milho foram levadas até o Departamento de Produção Vegetal (Setor de Agricultura), da ESALQ/USP, onde, com o auxílio de uma canjiqueira, obtinha-se a canjica e o farelo de milho, sendo a primeira levada até a Fecularia Santa Teresinha, no Município de Piracicaba-SP, onde era deixada em imersão em água, a qual era renovada diariamente, durante 3 dias, para posterior processamento e obtenção da farinha de milho.

\subsubsection{Milho pipoca}

A pipoca foi obtida através do preparo convencional em panela de alumínio com fina camada de óleo levada ao fogo em fogão a gás, e a pipoca obtida foi processada em processador de alimentos caseiro (multiprocessador Wallita Mega-Master). 


\subsection{Experimento de degradação e persistência}

\subsubsection{Tratamento dos grãos}

Para se proceder a aplicação do produto sobre os grãos de milho, trigo e milho pipoca, estes foram dispostos em fina camada sobre lona plástica, tendo sido aplicado então o inseticida nos grãos, na forma da emulsão preparada, de modo a se obter tratamento dos grãos na concentração teórica de 12 ppm do ingrediente ativo, com o auxílio de pulverizador costal mantido a pressão constante. Durante a aplicação os grãos eram revolvidos com o auxílio de um rodo, para se obter maior uniformidade possível na aplicação. Os grãos foram acondicionados em sacos plásticos mantidos fechados e guardados sob a bancada do laboratório, tendo sido feita uma coleta de amostras no dia da aplicação ( 0 dia), aos 15, 30, 60, 120 e 240 dias após o tratamento. Foram realizadas 264 analises, sendo 54 amostras de grãos e 144 de produtos processados (11 substratos x 3 repetições x 6 coletas =198), além de 66 amostras testemunha (11 substratos x 1 repetição x 6 coletas )

As análises de resíduos dos diversos substratos foram acompanhadas durante as oportunidades de sua realização, em cada período de coleta, sempre com uma amostra fortificada para melhor seguimento do processo analítico.

\subsection{Atividade residual de pirimifós-metil aos adultos de Sitophilus spp.}

\subsubsection{Tratamento dos grãos}

A etapa inicial deste experimento foi a aplicação do produto comercial Actellic 500 (500 g ingrediente ativo pirimifós-metil/L do produto comercial, $50 \% \mathrm{p} / \mathrm{v}$ ) sobre os grãos de trigo milho e milho pipoca. Esta operação foi realizada com o auxílio de um compressor de ar ao qual foi acoplada uma pistola de pintura, para se proceder a pulverização do produto sobre 
a massa de grãos.

Foram colocados $3 \mathrm{~kg}$ de grãos em sacos plásticos, de modo a se formar uma fina camada no fundo deste, para que se procedesse a aplicação da emulsão preparada de modo a se obter tratamento dos grãos na concentração teórica de 12 ppm do ingrediente ativo pirimifós-metil realizada então com a pistola de pintura, sobre os grãos que foram constantemente agitados durante a aplicação, para garantir uma cobertura homogênea, e ainda agitados por mais um tempo, após o término da aplicação.

Passados 15 dias da aplicação, foram retiradas amostras dos três tipos de grãos, e estes dispostos em potes plásticos, formando-se 5 repetições de $40 \mathrm{~g}$ para cada tipo de grão e infestada, cada parcela, com 40 adultos não sexados de Sitophilus spp., sendo igualmente montadas testemunhas com grãos não tratados. A avaliação da mortalidade foi feita 15 dias após a infestação, sendo considerados mortos os indivíduos imóveis, assim julgados incapazes de se locomoverem, mesmo quando instados por luz elétrica incandescente, colocada a poucos cm desses adultos.

Além das amostras de grãos retiradas aos 15 dias após aplicação do produto, foram também retiradas amostras aos 30 dias após e, a partir desta em intervalos mensais até 12 meses, sendo o procedimento idêntico ao anterior, com respeito à infestação e à avaliação da mortalidade dos insetos. 


\section{RESULTADOS E DISCUSSÃO}

\subsection{Limites de quantificação e porcentagens de recuperação do método analítico}

Nas Tabelas 1, 2 e 3 estão apresentados os resultados obtidos nos estudos de fortificação de pirimifós-metil em amostras de grãos de trigo, milho e milho pipoca, bem assim de seus respectivos produtos processados.

Os limites de quantificação para cada substrato podem variar dependendo da quantidade de interferentes e impurezas, principalmente óleos contidos em cada substrato utilizado. Os substratos ricos em óleos e pigmentos foram os que apresentaram o limite de quantificação mais alto, devido a interferência desses componentes nas análises, o que prejudica a resolução dos cromatogramas. 
Tabela 1. Porcentagem (\%) de recuperação de pirimifós-metil, pelo método de análise de resíduos em amostras de grãos de trigo e seus produtos processados.

\begin{tabular}{|c|c|c|c|c|c|c|c|}
\hline Produto & Repetições & Níveis & fortifica & o (mg.kg & & & \\
\hline & & 10 & 1 & 0,1 & 0,05 & 0,02 & 0,01 \\
\hline grãos & A B & 7981 & 7675 & 76104 & 7880 & $<\mathrm{LOQ}$ & $4 \mathrm{LOQ}$ \\
\hline & $<\mathrm{LOQ}<\mathrm{L}$ & & & & & & \\
\hline farelo & A B & 8580 & 8787 & 9687 & $<$ LOQ & $<\mathrm{LOQ}$ & $<\mathrm{LOQ}$ \\
\hline & $<\mathrm{LOQ}<\mathrm{L}$ & & & & & & \\
\hline farinha in & pral & A B & 9398 & 8183 & 7679 & $<\mathrm{LOQ}$ & $\Varangle \mathrm{LOQ}$ \\
\hline & $<\mathrm{LOQ}<\mathrm{L}$ & & $<\mathrm{LOQ}$ & LOQ & & & \\
\hline farinha br & & A B & 8476 & 96104 & 9488 & $<\mathrm{LOQ}$ & $\triangle \mathrm{LOQ}$ \\
\hline & $<\mathrm{LOQ}<\mathrm{L}$ & & $<\mathrm{LOQ}$ & $\mathrm{LOQ}$ & & & \\
\hline pão & A B & 8490 & 94101 & 8891 & $<\mathrm{LOQ}$ & $<\mathrm{LOQ}$ & $<\mathrm{LOQ}$ \\
\hline
\end{tabular}

* LOQ = Limite de quantificação, quando o nível de fortificação apresenta recuperação fora do intervalo de 75 a $125 \%$.

Tabela 2. Porcentagem (\%) de recuperação de pirimifós-metil, pelo método de análise de resíduos em amostras de grãos de milho e seus produtos processados.

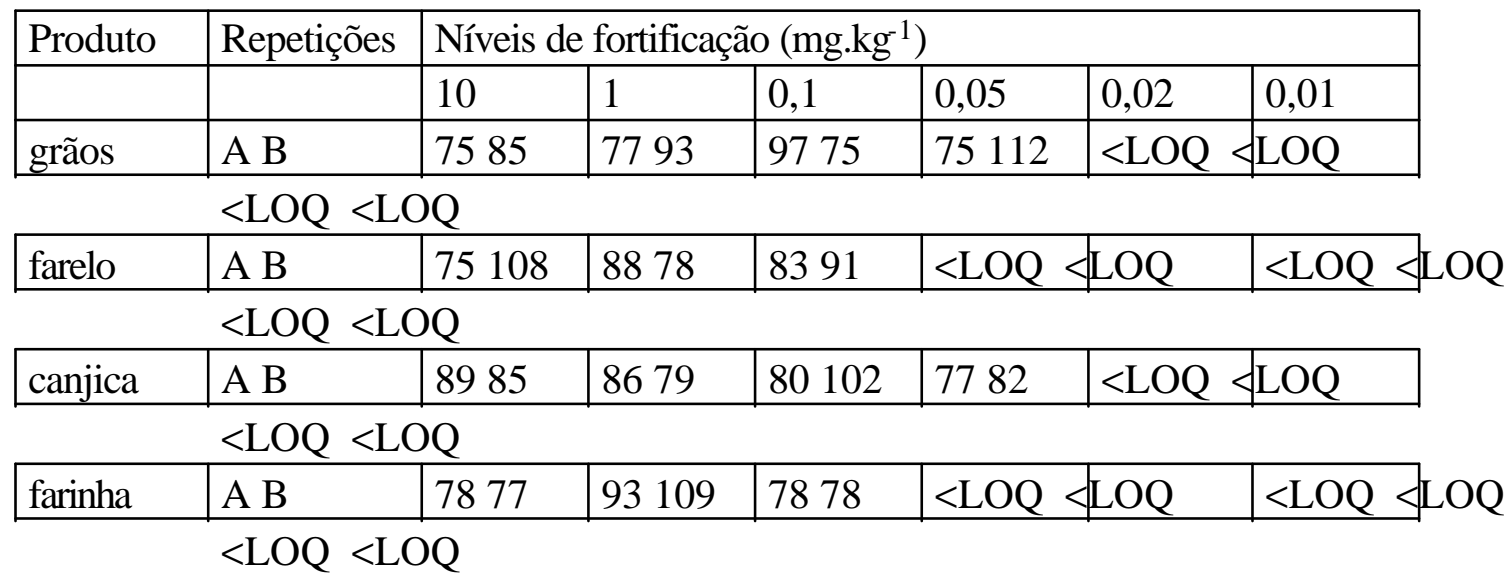

* LOQ = Limite de quantificação, quando o nível de fortificação apresenta recuperação fora do intervalo de 75 a $125 \%$. 
Tabela 3. Porcentagem (\%) de recuperação de pirimifós-metil, pelo método de análise de resíduos em amostras de grãos de milho pipoca e em pipoca.

\begin{tabular}{|c|c|c|c|c|c|c|c|}
\hline Produto & Repetições & \multicolumn{6}{|c|}{ Níveis de fortificação (mg.kg $\left.{ }^{-1}\right)$} \\
\hline & & 10 & 1 & 0,1 & 0,05 & 0,02 & 0,01 \\
\hline grãos & A B & 7983 & 9584 & 7578 & $<\mathrm{LOQ}$ & LOQ & $<\mathrm{LOQ}$ \\
\hline \multicolumn{8}{|c|}{$<\mathrm{LOQ}<\mathrm{LOQ}$} \\
\hline pipoca & A B & 8391 & 9386 & 9279 & 7575 & $<\mathrm{LO}$ & LOQ \\
\hline
\end{tabular}

* LOQ = Limite de quantificação, quando o nível de fortificação apresenta recuperação fora do intervalo de 75 a $125 \%$.

Assim pois, o método analítico adotado mostrou-se altamente satisfatório para as análises de resíduos de pirimifós-metil com recuperações variáveis de 75-104\% para trigo e seus produtos processados; de 75-112\% para o caso de milho e de 75-95\%, para a pipoca, com limites de quantificação de 0,05 e $0,1 \mathrm{mg}^{\mathrm{kg}}{ }^{-1}(\mathrm{ppm})$ para o trigo e produtos obtidos de seu processamento; de 0,02; 0,05 e 0,1 mg. $\mathrm{kg}^{-1}$ (ppm), para os de milho e 0,05 e $0,1 \mathrm{mg} \cdot \mathrm{kg}^{-1}$ (ppm), para o milho pipoca e seu produto processado (pipoca).

Os cromatogramas das fortificações determinadas como limites de quantificação para cada um dos substratos estudados, assim como das testemunhas e padrões das respectivas concentrações, são mostrados nas Figuras de 1 a 11. 


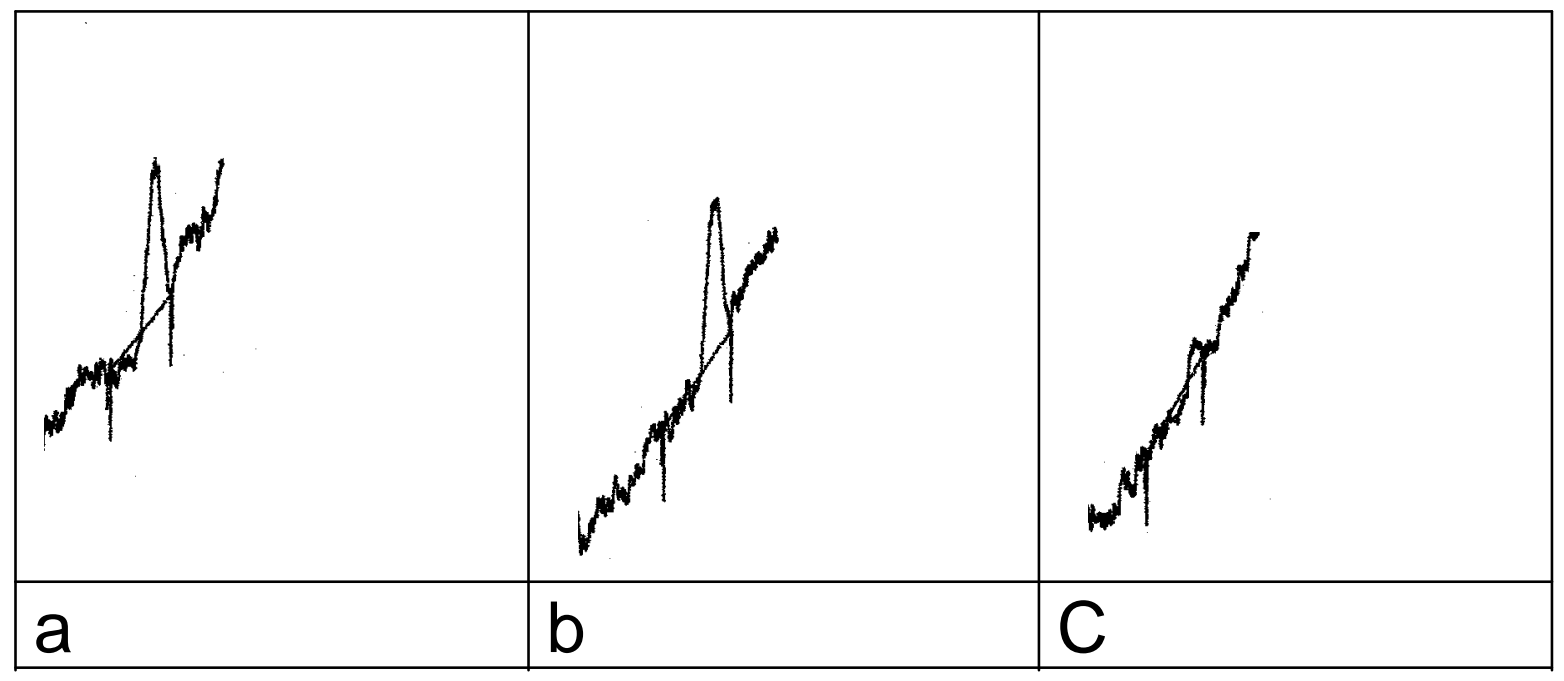

Figura 1 - Cromatogramas de extrato de grãos de trigo. a) padrão $2 \mu 1$ - 100 pg; b) fortificação de $0,05 \mathrm{mg} \cdot \mathrm{kg}^{-1} / 2 \mu \mathrm{l}-2 \mathrm{mg}$ - $100 \mathrm{pg}$; c) testemunha $2 \mu \mathrm{l}-2 \mathrm{mg}$. 


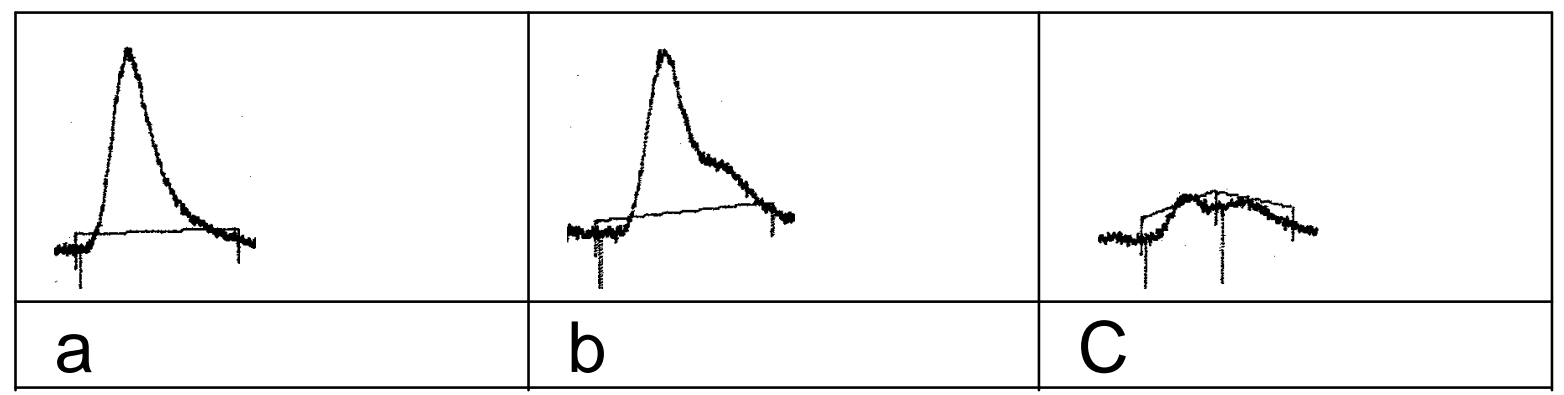

Figura 2 - Cromatogramas de extrato de farelo de trigo. a) padrão $2 \mu \mathrm{l}$ - 200 pg; b) fortificação de $0,1 \mathrm{mg} \cdot \mathrm{kg}^{-1} / 2 \mu \mathrm{l}-2 \mathrm{mg}$ - $200 \mathrm{pg}$; c) testemunha $2 \mu \mathrm{l}-2 \mathrm{mg}$. 


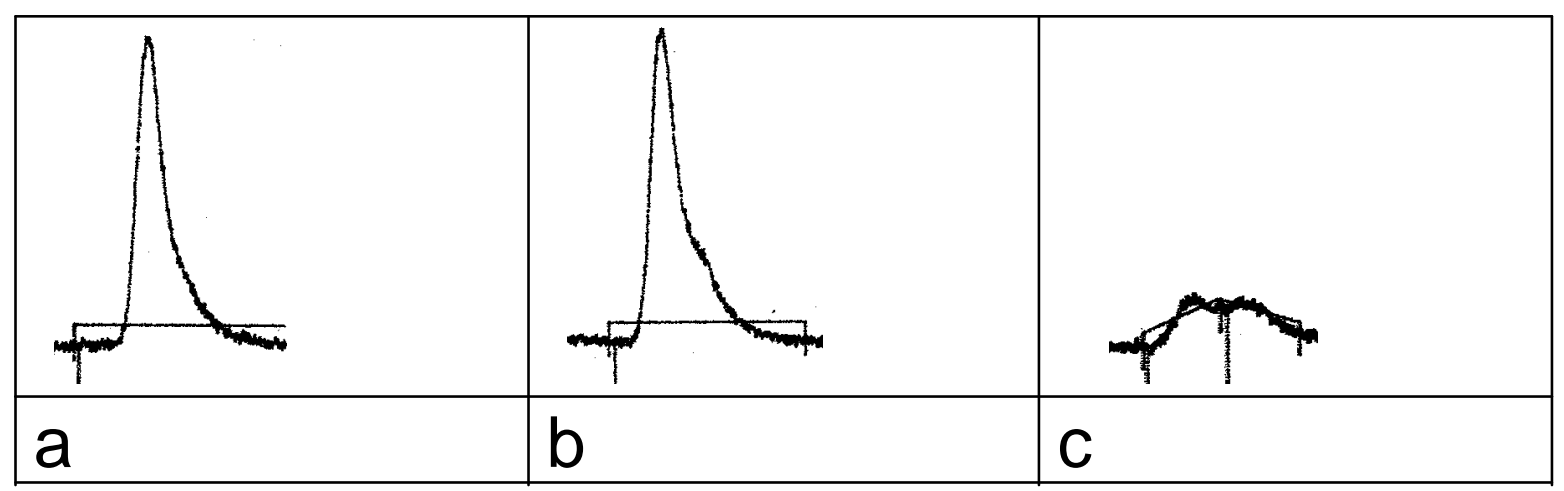

Figura 3 - Cromatogramas de extrato de farinha de trigo integral. a) padrão $2 \mu \mathrm{l}$ - 200 pg; b) fortificação de $0,1 \mathrm{mg} \cdot \mathrm{kg}^{-1} / 2 \mu \mathrm{l}-2 \mathrm{mg}$ - $200 \mathrm{pg}$; c) testemunha $2 \mu \mathrm{l}-2 \mathrm{mg}$. 


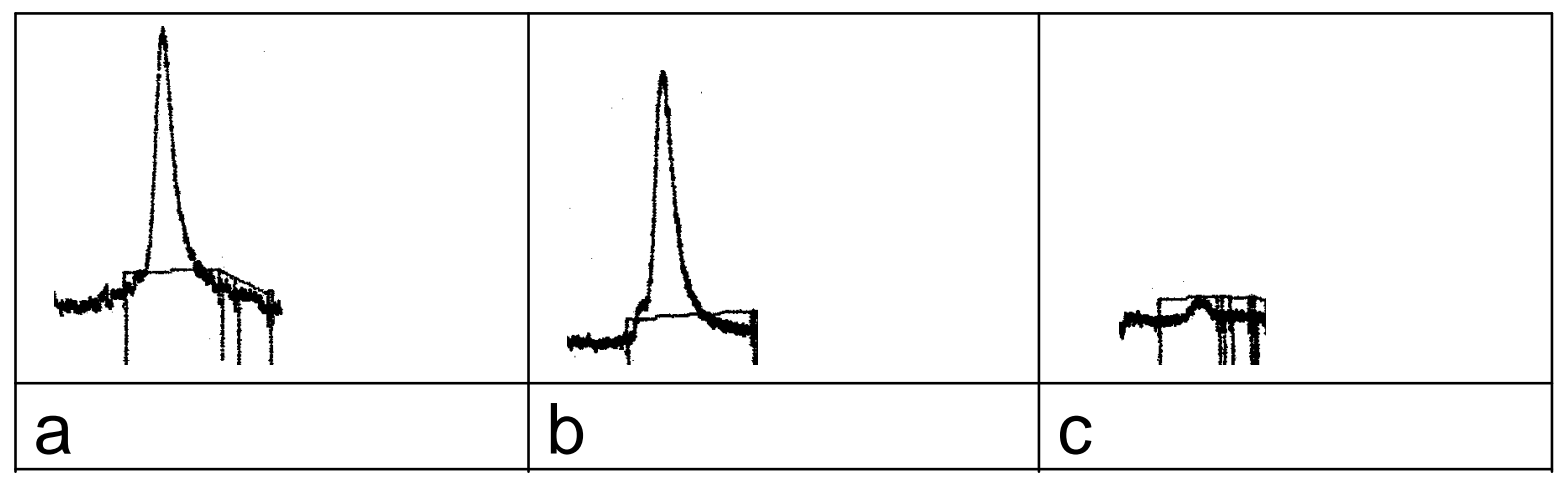

Figura 4 - Cromatogramas de extrato de farinha branca. a) padrão $2 \mu 1$ - 200 pg; b) fortificação de $0,1 \mathrm{mg} \cdot \mathrm{kg}^{-1} / 2 \mu \mathrm{l}-2 \mathrm{mg}$ - $200 \mathrm{pg}$; c) testemunha $2 \mu \mathrm{l}-2 \mathrm{mg}$. 


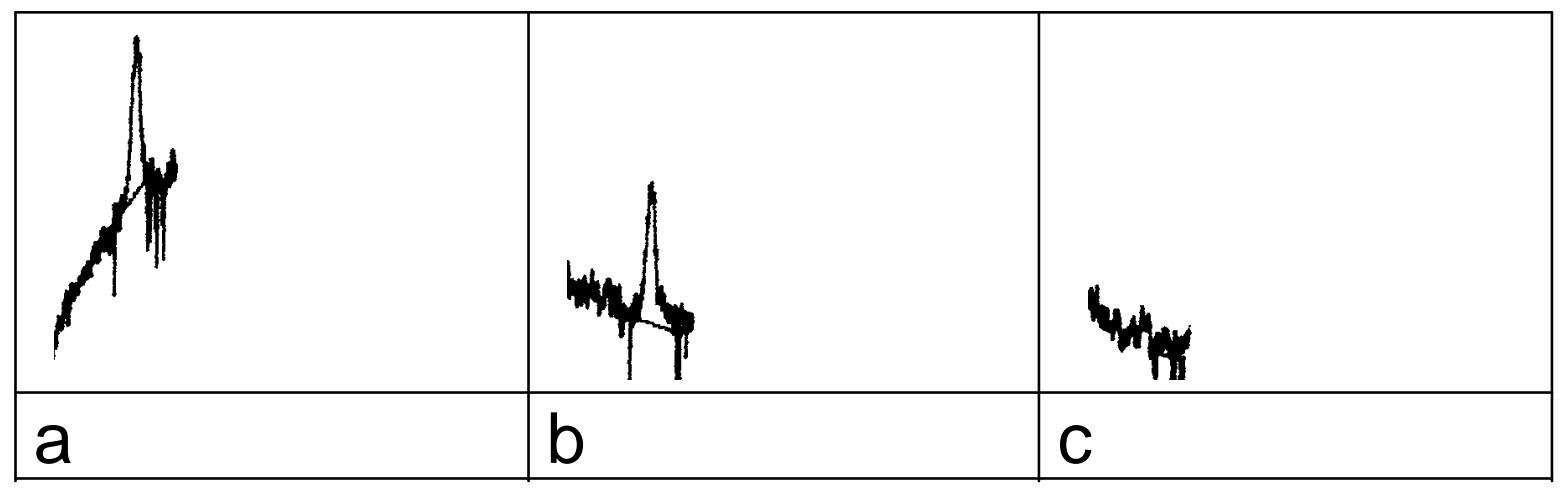

Figura 5 - Cromatogramas de extrato de pão. a) padrão $2 \mu \mathrm{l}$ - 200 pg; b) fortificação de 0,1

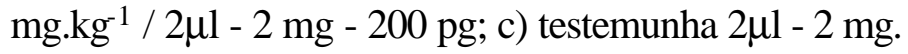




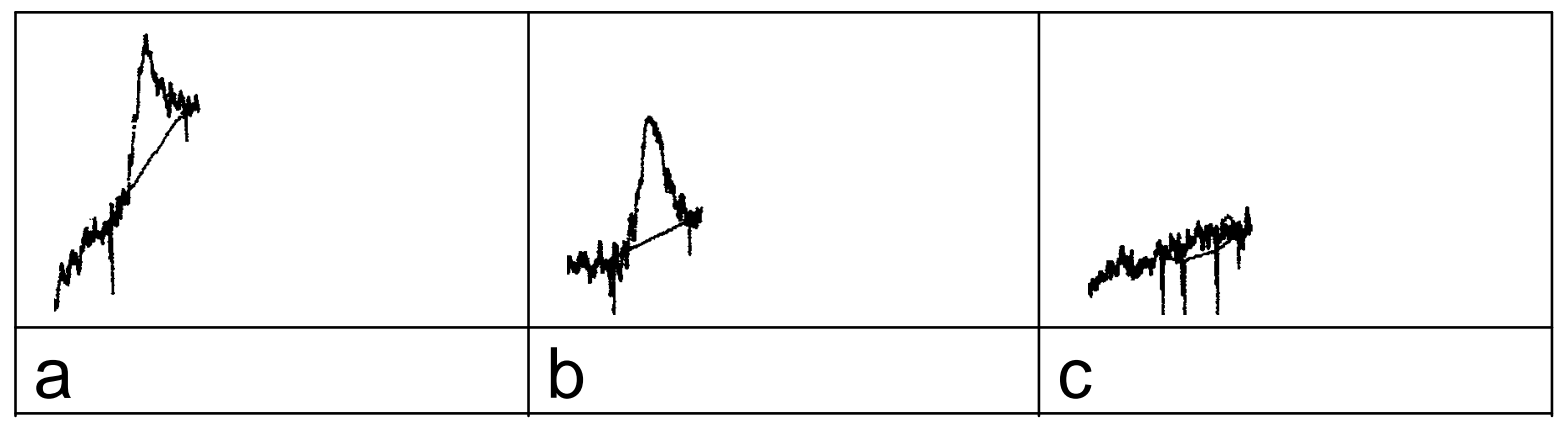

Figura 6 - Cromatogramas de extrato de grãos de milho. a) padrão $2 \mu 1$ - 100 pg; b) fortificação de $0,05 \mathrm{mg} \cdot \mathrm{kg}^{-1} / 2 \mu \mathrm{l}-2 \mathrm{mg}$ - $100 \mathrm{pg}$; c) testemunha $2 \mu \mathrm{l}-2 \mathrm{mg}$. 


\begin{tabular}{|l|l|l|}
\hline \\
\hline
\end{tabular}

Figura 7 - Cromatogramas de extrato de farelo de milho. a) padrão $2 \mu \mathrm{l}$ - 200 pg; b) fortificação de $0,1 \mathrm{mg} \cdot \mathrm{kg}^{-1} / 2 \mu \mathrm{l}-2 \mathrm{mg}-200 \mathrm{pg}$; c) testemunha $2 \mu \mathrm{l}-2 \mathrm{mg}$. 


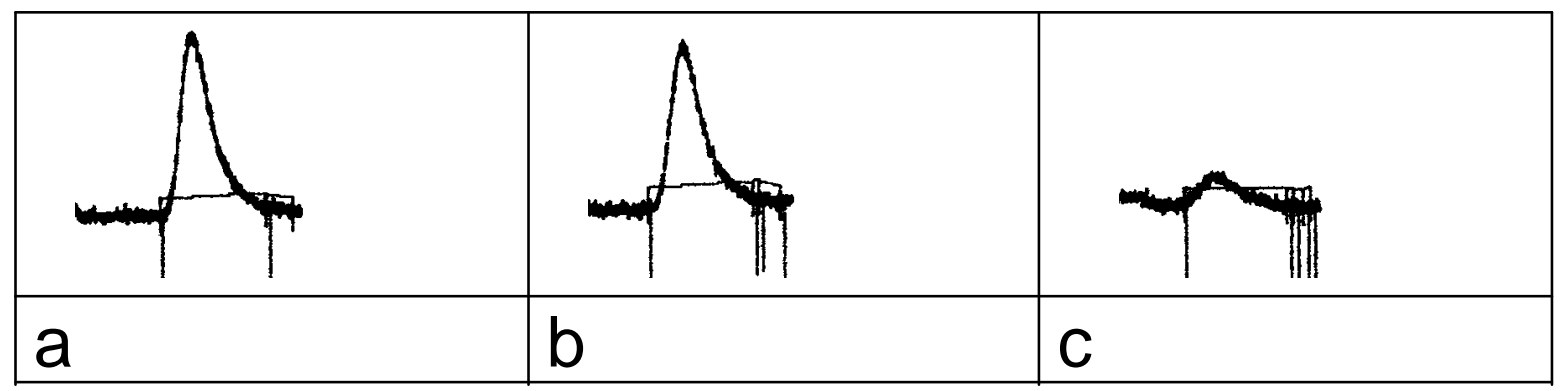

Figura 8 - Cromatogramas de extrato de grãos de milho canjicado (canjica). a) padrão $2 \mu l$ $100 \mathrm{pg}$; b) fortificação de $0,05 \mathrm{mg} \cdot \mathrm{kg}^{-1} / 2 \mu \mathrm{l}$ - $2 \mathrm{mg}$ - $100 \mathrm{pg}$; c) testemunha $2 \mu \mathrm{l}$ - 2 mg. 


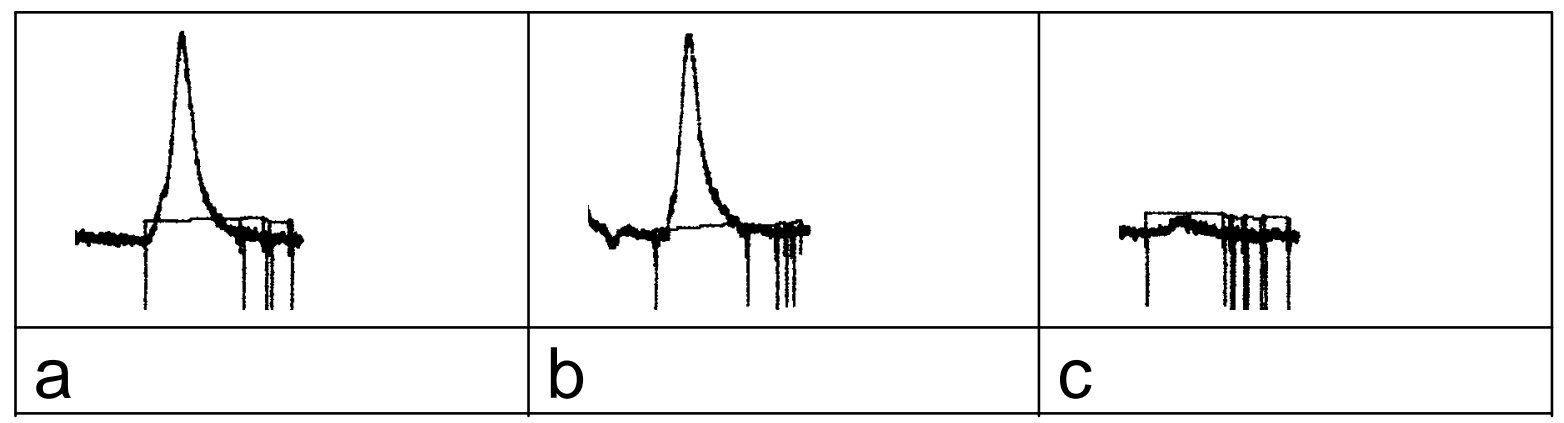

Figura 9 - Cromatogramas de extrato de farinha de milho. a) padrão $2 \mu \mathrm{l}$ - 200 pg; b) fortificação de $0,1 \mathrm{mg} \cdot \mathrm{kg}^{-1} / 2 \mu \mathrm{l}-2 \mathrm{mg}$ - $200 \mathrm{pg}$; c) testemunha $2 \mu \mathrm{l}$ - $2 \mathrm{mg}$. 


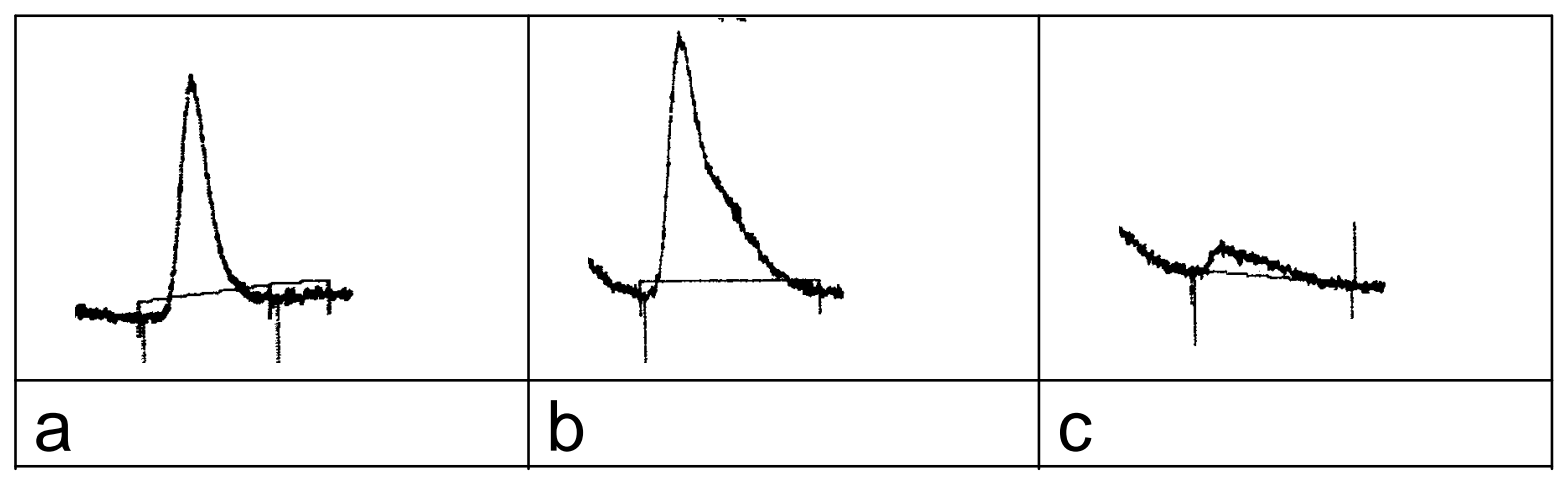

Figura 10 - Cromatogramas de extrato de milho pipoca. a) padrão $2 \mu \mathrm{l}$ - 200 pg; b) fortificação de $0,1 \mathrm{mg} \cdot \mathrm{kg}^{-1} / 2 \mu \mathrm{l}-2 \mathrm{mg}$ - $200 \mathrm{pg}$; c) testemunha $2 \mu \mathrm{l}-2 \mathrm{mg}$. 


\begin{tabular}{|l|l|l|}
\hline \\
\hline$a$
\end{tabular} \mid \begin{tabular}{c|c|}
\hline \\
\hline
\end{tabular}

Figura 11 - Cromatogramas de extrato de pipoca. a) padrão $2 \mu \mathrm{l}$ - 100 pg; b) fortificação de $0,05 \mathrm{mg} \cdot \mathrm{kg}^{-1} / 2 \mu \mathrm{l}-2 \mathrm{mg}-100 \mathrm{pg}$; c) testemunha $2 \mu \mathrm{l}-2 \mathrm{mg}$.

\subsection{Resíduos de pirimifós-metil em grãos de trigo e em seus produtos processados}

Os resultados obtidos das análises de grãos de trigo bem como de seus produtos processados, estão apresentados na Tabela 4. Todas as análises, correspondentes às amostras testemunhas, indicaram resíduos inferiores aos respectivos limites de quantificação.

De acordo com os dados obtidos, observa-se que a recuperação do produto aos zero dia ficou muito aquém da dosagem pretendida na aplicação, recuperando-se apenas 2,63 ppm, o que representa $22 \%$ da quantidade intencional de ingrediente ativo utilizada na aplicação. Bengston et al. (1984) obtiveram recuperação de 108\% de pirimifós-metil em grãos de trigo, e Mensah et al. (1979) alcançaram uma recuperação de 82\% decorridos um mês da aplicação do produto. O pesticida utilizado pode ser considerado de alta volatilidade, já que possui relativamente, alta pressão de vapor $\left(13 \mathrm{mPa}\right.$ a $30^{\circ} \mathrm{C}$, Tomlin, 1995), aliando esta característica do inseticida, ao fato de que a aplicação deste se fez em dia de temperaturas 
elevadas e em lugar descoberto; pode-se, desta forma, aceitar estes fatos como a possível explicação para os baixos níveis de depósito e portanto de recuperação já na análise inicial (zero dia).

O índice de degradação apresentado na Tabela 4 apresenta os valores de redução dos resíduos do inseticida de um período ao período subsequente; com isso pode-se observar a degradação do produto nos diferentes intervalos de tempo.

Na mesma tabela pode-se observar o índice de degradação acumulado, que representa a degradação do inseticida em todo o período, desde a primeira avaliação, onde é possível observar, por exemplo, para o caso de farinha branca, um índice acumulado de 6,98, indicando, então, que o teor inicial de pirimifós-metil neste substrato é quase 7 vezes maior que o resíduo ao final do período. Outros valores, variando de 3,86 - 5,85 foram encontrados para outros substratos.

Analisando as quantidades do produto nos derivados de trigo estudados, pode-se observar que houve uma grande concentração deste no farelo, que possui maior teor de óleo, assemelhando-se aos dados obtidos por Mensah et al. (1979) também Trevizan (1998) trabalhando com deltametrina, observou uma concentração do inseticida também no farelo, podendo-se então dizer que o produto permanece em maior parte no pericarpo, e em menor no endosperma. Esta concentração no farelo foi em torno de 2,8 vezes em relação ao grão inteiro, como pode ser observado no índice de concentração disposto na Tabela 5.

O pão preparado a partir da farinha branca obtida dos grãos tratados, apresentou grande redução nos teores dos resíduos, quando comparados com os obtidos nos grãos, sendo, em geral, menores do que $50 \%$ em relação àqueles.

Segundo Gelmini \& Novo (1987), a legislação estabelece que a tolerância e a carência são de 10 ppm e 30 dias respectivamente, para grãos armazenados submetidos ao tratamento com pirimifós-metil para controle de pragas durante o período de estocagem. Como a recomendação de aplicação do inseticida está abaixo do nível de tolerância estabelecido pela legislação $\left(6 \mathrm{mg} / \mathrm{kg}^{-1}\right)$, assim pode-se pensar a princípio, que os grãos tratados podem ser consumidos a qualquer momento, não necessitando ser respeitado tal período de carência; com isso vale salientar a necessidade de maior adequação e revisão da legislação por parte das autoridades competentes. 
Tabela 4. Resíduos de pirimifós-metil em grãos de trigo e em seus produtos processados.

\begin{tabular}{|c|c|c|c|c|c|c|c|}
\hline & & \multicolumn{3}{|c|}{ Repetições (ppm) } & Média & Índice de & Ind. de \\
\hline \multicolumn{8}{|l|}{ degr. } \\
\hline \multirow[t]{4}{*}{ Substrato } & Dias & A & $\mathrm{B}$ & $\mathrm{C}$ & $\mathrm{m} \pm \mathrm{dp}$ & degradação & \\
\hline & acum & lado & & & & & \\
\hline & 0 & 2,640 & 2,520 & 2,720 & $2,627 \pm 0,101$ & & \\
\hline & 15 & 2,320 & 2,160 & 2,640 & $2,373 \pm 0,244$ & 1,107 & 1,107 \\
\hline \multirow[t]{6}{*}{ grão } & 30 & 2,480 & 2,920 & 2,560 & $2,653 \pm 0,234$ & 0,894 & 0,990 \\
\hline & 60 & 1,224 & 1,246 & 1,278 & $1,249 \pm 0,027$ & 2,124 & 2,103 \\
\hline & 120 & 0,814 & 0,765 & 0,946 & $0,842 \pm 0,094$ & 1,483 & 3,120 \\
\hline & 240 & 0,609 & 0,634 & 0,701 & $0,648 \pm 0,048$ & 1,299 & 4,054 \\
\hline & 0 & 6,960 & 8,000 & 7,680 & $7,547 \pm 0,533$ & & \\
\hline & 15 & 6,860 & 6,340 & 6,020 & $6,407 \pm 0,424$ & 1,178 & 1,178 \\
\hline \multirow[t]{6}{*}{ farelo } & 30 & 4,600 & 5,560 & 6,060 & $5,407 \pm 0,742$ & 1,185 & 1,396 \\
\hline & 60 & 3,155 & 3,075 & 3,150 & $3,127 \pm 0,045$ & 1,729 & 2,413 \\
\hline & 120 & 2,241 & 2,584 & 2,007 & $2,277 \pm 0,291$ & 1,373 & 3,315 \\
\hline & 240 & 1,126 & 1,258 & 1,487 & $1,290 \pm 0,183$ & 1,765 & 5,850 \\
\hline & 0 & 2,511 & 2,610 & 2,370 & $2,497 \pm 0,121$ & & \\
\hline & 15 & 2,060 & 2,200 & 2,615 & $2,293 \pm 0,291$ & 1,089 & 1,089 \\
\hline farinha & 30 & 1,898 & 1,874 & 1,992 & $1,922 \pm 0,062$ & 1,193 & 1,299 \\
\hline \multirow[t]{5}{*}{ integral } & 60 & 1,626 & 1,644 & 1,662 & $1,644 \pm 0,018$ & 1,169 & 1,518 \\
\hline & 120 & 0,875 & 0,897 & 1,075 & $0,949 \pm 0,110$ & 1,732 & 2,631 \\
\hline & 240 & 0,627 & 0,661 & 0,648 & $0,646 \pm 0,017$ & 1,469 & 3,865 \\
\hline & 0 & 2,933 & 2,388 & 2,912 & $2,744 \pm 0,307$ & & \\
\hline & 15 & 2,458 & 2,275 & 2,211 & $2,313 \pm 0,129$ & 1,186 & 1,186 \\
\hline farinha & 30 & 1,701 & 1,478 & 1,734 & $1,637 \pm 0,136$ & 1,413 & 1,676 \\
\hline \multirow[t]{5}{*}{ branca } & 60 & 1,019 & 1,003 & 1,010 & $1,011 \pm 0,008$ & 1,619 & 2,714 \\
\hline & 120 & 0,559 & 0,551 & 0,594 & $0,568 \pm 0,023$ & 1,780 & 4,831 \\
\hline & 240 & 0,386 & 0,393 & 0,400 & $0,393 \pm 0,007$ & 1,445 & 6,982 \\
\hline & 0 & 1,097 & 1,133 & 1,145 & $1,125 \pm 0,025$ & & \\
\hline & 15 & 1,075 & 1,161 & 1,136 & $1,124 \pm 0,044$ & 1,001 & 1,001 \\
\hline \multirow[t]{4}{*}{ pão } & 30 & 1,174 & 1,065 & 1,000 & $1,080 \pm 0,088$ & 1,041 & 1,042 \\
\hline & 60 & 0,964 & 0,842 & 0,826 & $0,877 \pm 0,075$ & 1,231 & 1,283 \\
\hline & 120 & 0,387 & 0,338 & 0,425 & $0,383 \pm 0,044$ & 2,290 & 2,937 \\
\hline & 240 & 0,208 & 0,288 & 0,279 & $0,258 \pm 0,044$ & 1,485 & 4,360 \\
\hline
\end{tabular}


Tabela 5. Resíduos de pirimifós-metil em grãos de trigo e em seus produtos processados agrupados por período.

\begin{tabular}{|c|c|c|c|}
\hline Período (dias) & $\begin{array}{l}\text { Substrato } \\
\end{array}$ & Média (ppm) & Indice de \\
\hline \multicolumn{4}{|l|}{ concentração } \\
\hline & grão & 2,627 & \\
\hline & farelo & 7,547 & 2,873 \\
\hline \multirow[t]{5}{*}{0} & farinha integral & 2,497 & 0,951 \\
\hline & farinha branca & 2,744 & 1,045 \\
\hline & pão & 1,125 & 0,428 \\
\hline & grão & 2,373 & \\
\hline & farelo & 6,407 & 2,700 \\
\hline \multirow[t]{5}{*}{15} & farinha integral & 2,293 & 0,966 \\
\hline & farinha branca & 2,211 & 0,932 \\
\hline & pão & 1,124 & 0,474 \\
\hline & grão & 2,653 & \\
\hline & farelo & 5,407 & 2,038 \\
\hline \multirow[t]{5}{*}{30} & farinha integral & 1,922 & 0,724 \\
\hline & farinha branca & 1,637 & 0,617 \\
\hline & pão & 1,080 & 0,407 \\
\hline & grão & 1,249 & \\
\hline & farelo & 3,127 & 2,504 \\
\hline \multirow[t]{5}{*}{60} & farinha integral & 1,644 & 1,316 \\
\hline & farinha branca & 1,011 & 0,809 \\
\hline & pão & 0,877 & 0,702 \\
\hline & grão & 0,842 & \\
\hline & farelo & 2,277 & 2,704 \\
\hline \multirow[t]{5}{*}{120} & farinha integral & 0,949 & 1,127 \\
\hline & farinha branca & 0,568 & 0,675 \\
\hline & pão & 0,383 & 0,455 \\
\hline & grão & 0,648 & \\
\hline & farelo & 1,290 & 1,991 \\
\hline \multirow[t]{3}{*}{240} & farinha integral & 0,646 & 0,997 \\
\hline & farinha branca & 0,393 & 0,606 \\
\hline & pão & 0,258 & 0,398 \\
\hline
\end{tabular}




\subsection{Resíduos de pirimifós-metil em grãos de milho e em seus produtos processados}

Os resultados obtidos das análises de grãos de milho bem como de seus produtos processados, estão apresentados na Tabela 6. Igualmente, todos os dados obtidos, relativos às amostras testemunhas, revelaram-se inferiores aos respectivos limites de quantificação.

Analisando a Tabela 6 nota-se que o resíduo ao zero dia, está também muito abaixo da dosagem aplicada, valendo aqui as mesmas considerações aventadas para o caso do trigo, apesar de se ter conseguido um depósito maior para o milho, do que para os outros dois tipos de grãos. Segundo os dados, houve uma recuperação de cerca de 4 ppm o que significa 33\% da dosagem pretendida na aplicação.

Alleoni (1995), trabalhando com pirimifós-metil a 12 ppm, obteve uma recuperação de 77\%, também ao zero dia, mas na dosagem 6 ppm, obteve uma recuperação de $67 \%$, semelhante à LaHue(1975), que conseguiu recuperação de cerca de 80\% trabalhando com 10 ppm, analisando os grãos 24 horas após a aplicação.

A observação dos dados mostra relativa persistência do inseticida nos primeiros 30 dias decorridos da aplicação, tendo uma redução de aproximadamente 17\%, já nos 30 dias subseqüentes; no período de 30 a 60 dias, a degradação foi bem maior, apresentando redução em torno de $56 \%$

Comparando-se os resultados dos diferentes substratos analisados, pode-se observar uma concentração de pirimifós-metil na parte externa dos grãos, já que o farelo (rico em óleo, relativamente) apresentou maiores teores do inseticida que os grãos, como pode ser observado pelo índice de concentração apresentado na Tabela 7; a canjica, que trata-se basicamente do endosperma do milho, apresentou teores relativamente bem mais baixos dos resíduos.

Trevizan (1998), trabalhando com deltametrina em grãos de milho e seus produtos processados, obteve resultados semelhantes, com alta concentração do inseticida no farelo e quantidades muito pequenas na canjica e na farinha.

Também, neste caso, a recomendação de tratamento na concentração de $6 \mathrm{mg} \cdot \mathrm{kg}^{-1}$, para controle das pragas do armazenamento, está abaixo da tolerância legal (10 mg.kg-1 ). Isso, novamente, quer dizer que, a princípio, esses grãos alimentícios poderiam ser consumidos 
mesmo logo após o tratamento. Assim, igualmente, a legislação está inadequada à realidade. 
Tabela 6. Resíduos de pirimifós-metil em grãos de milho e em seus produtos processados.

\begin{tabular}{|c|c|c|c|c|c|c|c|}
\hline & & \multicolumn{3}{|c|}{ Repetições (ppm) } & Média & Indice de & Ind. de \\
\hline \multicolumn{8}{|l|}{ degr. } \\
\hline \multirow[t]{4}{*}{ Substrato } & Dias & A & $\mathrm{B}$ & $\mathrm{C}$ & $\mathrm{m}+\mathrm{dp}$ & degradação & \\
\hline & acum & lado & & & & & \\
\hline & 0 & 3,980 & 3,800 & 4,100 & $3,960 \pm 0,150$ & & \\
\hline & 15 & 3,470 & 3,660 & 3,590 & $3,573 \pm 0,096$ & 1,108 & 1,108 \\
\hline \multirow[t]{6}{*}{ grão } & 30 & 2,870 & 3,780 & 3,250 & $3,300 \pm 0,457$ & 1,083 & 1,200 \\
\hline & 60 & 1,632 & 1,437 & 1,253 & $1,441 \pm 0,189$ & 2,290 & 2,748 \\
\hline & 120 & 0,977 & 1,075 & 1,376 & $1,143 \pm 0,208$ & 1,261 & 3,465 \\
\hline & 240 & 0,629 & 0,522 & 0,610 & $0,587 \pm 0,057$ & 1,947 & 6,746 \\
\hline & 0 & 5,450 & 6,350 & 6,770 & $6,190 \pm 0,674$ & & \\
\hline & 15 & 5,320 & 4,480 & 5,080 & $4,960 \pm 0,433$ & 1,248 & 1,248 \\
\hline \multirow[t]{6}{*}{ farelo } & 30 & 3,460 & 4,340 & 4,100 & $3,967 \pm 0,455$ & 1,250 & 1,560 \\
\hline & 60 & 2,805 & 3,092 & 2,839 & $2,912 \pm 0,157$ & 1,362 & 2,126 \\
\hline & 120 & 2,379 & 2,373 & 2,450 & $2,401 \pm 0,043$ & 1,213 & 2,578 \\
\hline & 240 & 1,237 & 1,125 & 1,058 & $1,140 \pm 0,090$ & 2,106 & 5,430 \\
\hline & 0 & 0,066 & 0,068 & 0,071 & $0,068 \pm 0,003$ & & \\
\hline & 15 & 0,051 & 0,048 & 0,046 & $0,048 \pm 0,003$ & 1,417 & 1,417 \\
\hline \multirow[t]{6}{*}{ canjica } & 30 & 0,101 & 0,040 & 0,072 & $0,071 \pm 0,031$ & 0,676 & 0,958 \\
\hline & 60 & 0,090 & 0,062 & 0,060 & $0,070 \pm 0,016$ & 1,014 & 0,971 \\
\hline & 120 & 0,085 & 0,065 & 0,069 & $0,073 \pm 0,011$ & 0,959 & 0,932 \\
\hline & 240 & 0,075 & 0,059 & 0,057 & $0,064 \pm 0,010$ & 1,141 & 1,062 \\
\hline & 0 & 0,074 & 0,162 & 0,145 & $0,127 \pm 0,047$ & & \\
\hline & 15 & 0,047 & 0,044 & 0,122 & $0,071 \pm 0,044$ & 1,789 & 1,789 \\
\hline \multirow[t]{4}{*}{ farinha } & 30 & 0,181 & 0,076 & 0,105 & $0,121 \pm 0,054$ & 0,587 & 1,049 \\
\hline & 60 & 0,097 & 0,100 & 0,079 & $0,092 \pm 0,011$ & 1,315 & 1,380 \\
\hline & 120 & 0,086 & 0,077 & 0,076 & $0,080 \pm 0,006$ & 1,150 & 1,587 \\
\hline & 240 & 0,066 & 0,059 & 0,050 & $0,058 \pm 0,008$ & 1,379 & 2,190 \\
\hline
\end{tabular}


Tabela 7. Resíduos de pirimifós-metil em grãos de milho e em seus produtos processados agrupados por período.

\begin{tabular}{|c|c|c|c|}
\hline Período (dias) & Substrato & Média (ppm) & Índice de \\
\hline \multicolumn{4}{|l|}{ concentração } \\
\hline & grão & 3,960 & \\
\hline & farelo & 6,190 & 1,563 \\
\hline \multirow[t]{4}{*}{0} & canjica & 0,068 & 0,017 \\
\hline & farinha & 0,127 & 0,032 \\
\hline & grão & 3,573 & \\
\hline & farelo & 4,960 & 1,388 \\
\hline \multirow[t]{4}{*}{15} & canjica & 0,048 & 0,013 \\
\hline & farinha & 0,071 & 0,020 \\
\hline & grão & 3,300 & \\
\hline & farelo & 3,967 & 1,202 \\
\hline \multirow[t]{4}{*}{30} & canjica & 0,071 & 0,021 \\
\hline & farinha & 0,121 & 0,037 \\
\hline & grão & 1,441 & \\
\hline & farelo & 2,912 & 2,021 \\
\hline \multirow[t]{4}{*}{60} & canjica & 0,070 & 0,049 \\
\hline & farinha & 0,092 & 0,064 \\
\hline & grão & 1,143 & \\
\hline & farelo & 2,401 & 2,101 \\
\hline \multirow[t]{4}{*}{120} & canjica & 0,073 & 0,064 \\
\hline & farinha & 0,080 & 0,070 \\
\hline & grão & 0,587 & \\
\hline & farelo & 1,140 & 1,942 \\
\hline \multirow[t]{2}{*}{240} & canjica & 0,064 & 0,109 \\
\hline & farinha & 0,058 & 0,099 \\
\hline
\end{tabular}




\subsection{Resíduos de pirimifós-metil em milho pipoca e pipoca}

Os resultados obtidos das análises de grãos de milho pipoca bem como de pipoca, estão apresentados na Tabela 8. Também, as amostras testemunhas tiveram resultados indicando resíduos inferiores aos limites de quantificação dos respectivos métodos.

Pela tabela, nota-se que o resíduo obtido ao zero dia, está novamente, muito abaixo da dosagem aplicada, sugerindo, outra vez, que o depósito foi extremamente afetado pelos mesmos fatores citados anteriormente. Segundo os dados, houve uma recuperação de 2,15 ppm o que significa $18 \%$ da dosagem pretendida na aplicação; este dado é ainda menor do que os conseguidos para o trigo.

Ao se analisar a pipoca preparada a partir do grão tratado, pode-se observar uma pequena redução no teor de pirimifós-metil neste substrato, em relação ao grão, dado condizente com o de Singh \& Chawla (1980), citados por Trevizan (1998), que por sua vez, obteve uma concentração média de 1,58 vezes de deltametrina na pipoca preparada, quando comparada ao grão.

Com base nestes dados pode-se dizer que também para milho pipoca é necessário se fazer mais estudos no sentido de se adequar melhor a legislação pertinente ao tratamento de grãos armazenados. 
Tabela 8. Resíduos de pirimifós-metil em grãos de milho pipoca e em pipoca.

\begin{tabular}{|c|c|c|c|c|c|c|c|}
\hline & & \multicolumn{3}{|c|}{ Repetições (ppm) } & Média & Indice de & Ind. de \\
\hline \multicolumn{8}{|l|}{ degr. } \\
\hline \multirow[t]{2}{*}{ Substrato } & Dias & A & B & $\mathrm{C}$ & $\mathrm{m} \pm \mathrm{dp}$ & degradação & \\
\hline & \multicolumn{7}{|c|}{ acumulado } \\
\hline \multirow[t]{3}{*}{ grão } & 0 & 2,104 & 2,103 & 2,244 & $2,150 \pm 0,081$ & & \\
\hline & 15 & 1,471 & 1,605 & 1,377 & $1,484 \pm 0,115$ & 1,449 & 1,449 \\
\hline & 30 & 1,139 & 0,987 & 1,019 & $1,048 \pm 0,080$ & 1,416 & 2,052 \\
\hline & & & & & & & \\
\hline & 60 & 0,880 & 0,951 & 1,102 & $0,978 \pm 0,113$ & 1,072 & 2,198 \\
\hline & 120 & 0,812 & 0,731 & 0,711 & $0,751 \pm 0,053$ & 1,302 & 2,863 \\
\hline & & & & & & & \\
\hline & 240 & 0,397 & 0,420 & 0,335 & $0,384 \pm 0,044$ & 1,956 & 5,599 \\
\hline & & & & & & & \\
\hline & 0 & 1,934 & 1,830 & 1,976 & $1,913 \pm 0,075$ & & \\
\hline & 15 & 1,377 & 1,262 & 1,285 & $1,308 \pm 0,061$ & 1,463 & 1,463 \\
\hline pipoca & 30 & 1,075 & 1,257 & 1,254 & $1,195 \pm 0,104$ & 1,095 & 1,601 \\
\hline & 60 & 0.877 & 0.832 & 0.785 & $0.831+0.046$ & 1438 & 2.302 \\
\hline & & & & & & & \\
\hline & 120 & 0,661 & 0,596 & 0,760 & $0,672 \pm 0,083$ & 1,237 & 2,847 \\
\hline & 240 & 0,232 & 0,262 & 0,250 & $0,248 \pm 0,015$ & 2,710 & 7,714 \\
\hline
\end{tabular}

Tabela 9. Resíduos de pirimifós-metil em grãos de milho pipoca e em pipoca agrupados por período.

\begin{tabular}{|c|c|c|c|}
\hline Período (dias) & Substrato & Média (ppm) & Indice de \\
\hline \multicolumn{4}{|l|}{ concentração } \\
\hline \multirow[t]{2}{*}{0} & grão & 2,150 & \\
\hline & pipoca & 1,913 & 0,890 \\
\hline \multirow[t]{2}{*}{15} & grão & 1.484 & \\
\hline & pipoca & 1,308 & 0,881 \\
\hline 30 & grão & 1,048 & \\
\hline
\end{tabular}




\begin{tabular}{|l|l|l|l|}
\hline & pipoca & 1,195 & 1,140 \\
\hline 60 & grão & 0,978 & \\
\hline & pipoca & 0,831 & 0,850 \\
\hline 120 & grão & 0,751 & \\
\hline & pipoca & 0,672 & 0,895 \\
\hline 240 & grão & 0,384 & \\
\hline & pipoca & 0,248 & 0,646 \\
\hline
\end{tabular}




\subsection{Efeito residual de pirimifós-metil aos adultos de Sitophilus spp.}

As avaliações acerca da ação residual de pirimifós-metil, baseando-se na mortalidade dos insetos, acham-se nas Tabelas de 10 a 22. As mortalidades corrigidas foram obtidas através da fórmula de Abbott ${ }^{(1)}$.

Os resultados obtidos pelas avaliações de mortalidade de Sitophilus spp. sobre grãos de trigo, milho e milho pipoca tratados com 12 ppm de pirimifós-metil, mostra que o inseticida foi bastante eficiente no controle da praga, causando uma mortalidade de $100 \%$ até 150 dias após o tratamento, e ainda depois disso, a mortalidade manteve-se acima de $90 \%$ até o final das avaliações, que foram feitas por um período total de 360 dias decorridos da aplicação do inseticida.

Campos et al. (1991) concluíram que pirimifós-metil foi eficiente no controle de Sitophilus oryzae (L.,1763) 180 dias após a aplicação do inseticida. Bitran et al. (1991) citaram que pirimifós-metil foi o melhor inseticida para grãos de milho infestados com $S$. zeamais Mots., 1855, sendo ainda o melhor para a proteção do trigo e do arroz no controle de S. oryzae (L.,1763). 
Tabela 10. Número de adultos de Sitophilus spp. mortos por parcela, em amostras tratadas (A) e testemunha (B) 15 dias após aplicação..

\begin{tabular}{|l|l|l|l|l|l|}
\hline Grão & Tratam. & Repetições & Média & Mortalidade & Mort. \\
\hline
\end{tabular}

\begin{tabular}{|l|l|l|l|l|l|l|l|l|l|}
\hline & & 1 & 2 & 3 & 4 & 5 & & $(\%)$ & \\
\hline Trigo & A B & 400 & 401 & 400 & 400 & 401 & 400,4 & 1001 & 100 \\
\hline Milho & A B & 401 & 400 & 402 & 400 & 401 & 400,8 & 1002 & 100 \\
\hline Milho Pipoca & A B & 400 & 403 & 401 & 400 & 402 & 401,2 & 1003 \\
\hline
\end{tabular}

100

Tabela 11. Número de adultos de Sitophilus spp. mortos por parcela, em amostras tratadas (A) e testemunha (B) 30 dias após aplicação..

\begin{tabular}{|c|c|c|c|c|c|c|c|c|c|}
\hline Grão & Tratam. & \multicolumn{5}{|c|}{ Repetições } & Média & Mortalidade & Mort. \\
\hline & & 1 & 2 & 3 & 4 & 5 & & $(\%)$ & \\
\hline & corrigida & & & & & & & & \\
\hline Trigo & A B & 400 & 400 & 400 & 400 & 400 & 400 & 1000 & 100 \\
\hline Milho & A B & 400 & 400 & 400 & 400 & 400 & 400 & 1000 & 100 \\
\hline Milho & poca & A B & 400 & 400 & 401 & 400 & 400 & 400,2 & 100 \\
\hline
\end{tabular}


Tabela 12. Número de adultos de Sitophilus spp. mortos por parcela, em amostras tratadas (A) e testemunha (B) 60 dias após aplicação..

\begin{tabular}{|l|l|l|l|l|l|}
\hline Grão & Tratam. & Repetições & Média & Mortalidade & Mort. \\
\hline
\end{tabular}

\begin{tabular}{|l|l|l|l|l|l|l|l|l|l|}
\hline & & 1 & 2 & 3 & 4 & 5 & & $(\%)$ & \\
\hline Trigo & A B & 400 & 400 & 400 & 400 & 400 & 400 & 1000 & 100 \\
\hline Milho & A B & 401 & 400 & 400 & 400 & 400 & 400,2 & 1000,5 & 100 \\
\hline Milho Pipoca & A B & 401 & 402 & 401 & 400 & 400 & 400,8 & 1002 \\
\hline
\end{tabular}

100

Tabela 13. Número de adultos de Sitophilus spp. mortos por parcela, em amostras tratadas (A) e testemunha (B) 90 dias após aplicação..

\begin{tabular}{|c|c|c|c|c|c|c|c|c|c|}
\hline Grão & Tratam. & \multicolumn{5}{|c|}{ Repetições } & Média & Mortalidade & Mort. \\
\hline & & 1 & 2 & 3 & 4 & 5 & & $(\%)$ & \\
\hline \multicolumn{10}{|c|}{ corrigida } \\
\hline Trigo & $\mathrm{AB}$ & 401 & 400 & 402 & 400 & 402 & 401 & 1002,5 & 100 \\
\hline Milho & A B & 400 & 401 & 401 & 400 & 400 & 400,4 & 1001 & 100 \\
\hline Milho F & poca & A B & 402 & 402 & 403 & 403 & 400 & 402 & 1005 \\
\hline
\end{tabular}


Tabela 14. Número de adultos de Sitophilus spp. mortos por parcela, em amostras tratadas (A) e testemunha (B) 120 dias após aplicação..

\begin{tabular}{|l|l|l|l|l|l|}
\hline Grão & Tratam. & Repetições & Média & Mortalidade & Mort. \\
\hline
\end{tabular}

\begin{tabular}{|l|l|l|l|l|l|l|l|l|l|}
\hline & & 1 & 2 & 3 & 4 & 5 & & $(\%)$ & \\
\hline Trigo & A B & 401 & 402 & 400 & 400 & 401 & 400,8 & 1002 & 100 \\
\hline Milho & A B & 400 & 400 & 400 & 400 & 401 & 400,2 & 1000,5 & 100 \\
\hline Milho Pipoca & A B & 400 & 400 & 401 & 401 & 401 & 400,6 & 100 \\
\hline
\end{tabular}

$1,5 \quad 100$

Tabela 15. Número de adultos de Sitophilus spp. mortos por parcela, em amostras tratadas (A) e testemunha (B) 150 dias após aplicação.

\begin{tabular}{|c|c|c|c|c|c|c|c|c|c|}
\hline Grão & Amostra & \multicolumn{5}{|c|}{ Repetições } & Média & Mortalidade & Mort. \\
\hline & & 1 & 2 & 3 & 4 & 5 & & $(\%)$ & \\
\hline & corrigida & & & & & & & & \\
\hline Trigo & A B & 400 & 401 & 400 & 401 & 401 & 400,6 & 1001,5 & 100 \\
\hline Milho & A B & 400 & 401 & 400 & 400 & 400 & 400,2 & 1000,5 & 100 \\
\hline Milho & poca & A B & 400 & 400 & 401 & 400 & 400 & 400,2 & 100 \\
\hline
\end{tabular}


Tabela 16. Número de adultos de Sitophilus spp. mortos por parcela, em amostras tratadas (A) e testemunha (B) 180 dias após aplicação..

\begin{tabular}{|l|l|l|l|l|l|}
\hline Grão & Tratam. & Repetições & Média & Mortalidade & Mort. \\
\hline
\end{tabular}

\begin{tabular}{|c|c|c|c|c|c|c|c|c|c|}
\hline & & 1 & 2 & 3 & 4 & 5 & & $(\%)$ & \\
\hline \multicolumn{10}{|c|}{ corrigida } \\
\hline Trigo & A B & 4011 & 408 & 4015 & 409 & 4010 & \multicolumn{2}{|l|}{4010,6} & 100 \\
\hline 26,5 & \multicolumn{9}{|l|}{100} \\
\hline Milho & A B & 4012 & 398 & 4019 & 4014 & 406 & \multicolumn{2}{|c|}{\begin{tabular}{ll|l}
39,8 & 11,8 \\
\end{tabular}} & 99,5 \\
\hline 29,5 & \multicolumn{9}{|l|}{99} \\
\hline Milho & poca & A B & 408 & 407 & 409 & 395 & 403 & $39,86,4$ & 99,5 \\
\hline
\end{tabular}

Tabela 17. Número de adultos de Sitophilus spp. mortos por parcela, em amostras tratadas (A) e testemunha (B) 210 dias após aplicação..

\begin{tabular}{|c|c|c|c|c|c|c|c|c|c|}
\hline \multirow[t]{2}{*}{ Grão } & Tratam. & \multicolumn{5}{|c|}{ Repetições } & Média & Mortalidade & Mort. \\
\hline & & 1 & 2 & 3 & 4 & 5 & & (\%) & \\
\hline & \multicolumn{9}{|c|}{ corrigida } \\
\hline Trigo & A B & 405 & 408 & 406 & 405 & 404 & 405,6 & 10014 & 100 \\
\hline Milho & A B & 402 & 405 & 404 & 393 & 392 & \multicolumn{2}{|c|}{$39,63,2$} & 998 \\
\hline \multicolumn{10}{|c|}{99} \\
\hline Milho & poca & A B & 403 & 393 & 392 & 404 & 393 & 39,43 & 98,5 \\
\hline
\end{tabular}

Tabela 18. Número de adultos de Sitophilus spp. mortos por parcela, em amostras tratadas 
(A) e testemunha (B) 240 dias após aplicação..

\begin{tabular}{|c|c|c|c|c|c|c|c|c|c|}
\hline Grão & Tratam. & Repet & & & & & Média & Mortalidade & Mort. \\
\hline & & 1 & 2 & 3 & 4 & 5 & & $(\%)$ & \\
\hline & corrigid & & & & & & & & \\
\hline Trigo & A B & 408 & 396 & 406 & 395 & 388 & 39,26, & & 98 \\
\hline 16,5 & 98 & & & & & & & & \\
\hline Milho & A B & 382 & 408 & 397 & 3810 & 379 & 38,47, & & 9618 \\
\hline & 95 & & & & & & & & \\
\hline Milho & poca & A B & 402 & 392 & 403 & 400 & 375 & $39,22,4$ & 986 \\
\hline
\end{tabular}

Tabela 19. Número de adultos de Sitophilus spp. mortos por parcela, em amostras tratadas (A) e testemunha (B) 270 dias após aplicação..

\begin{tabular}{|l|l|l|l|l|l|l|l|l|l|}
\hline Grão & Tratam. & Repetições & Média & Mortalidade & Mort. \\
\hline & & 1 & 2 & 3 & 4 & 5 & & $(\%)$ & \\
\hline
\end{tabular}
\begin{tabular}{|l|l|l|l|l|l|l|l|l|l|l|}
\hline Trigo & A B & 3811 & 409 & 4014 & 4019 & 3913 & $39,413,2$ & 98,5 \\
\hline 33 & 98 & 4013 & 398 & 3914 & 3816 & 3914 & 3913 & $97,532,5$ & 96 \\
\hline Milho & A B & A B & 3810 & 3912 & 398 & 378 & 3911 & $38,49,8$ & 96 \\
\hline Milho Pipoca & A porigida \\
\hline
\end{tabular}
$24,5 \quad 95$

Tabela 20. Número de adultos de Sitophilus spp. mortos por parcela, em amostras tratadas (A) e testemunha (B) 300 dias após aplicação..

\begin{tabular}{|l|l|l|l|l|l|}
\hline Grão & Tratam. & Repetições & Média & Mortalidade & Mort. \\
\hline
\end{tabular}




\begin{tabular}{|c|c|c|c|c|c|c|c|c|c|}
\hline & & 1 & 2 & 3 & 4 & 5 & & $(\%)$ & \\
\hline \multicolumn{10}{|c|}{ corrigida } \\
\hline Trigo & A B & 3910 & 408 & 408 & 377 & 3811 & \multicolumn{2}{|l|}{$38,88, \$$} & 9722 \\
\hline \multicolumn{10}{|c|}{96} \\
\hline Milho & A B & 374 & 4012 & 409 & 3611 & $38 \quad 10$ & \multicolumn{2}{|l|}{$38,29,2$} & 95,5 \\
\hline 23 & \multicolumn{9}{|l|}{94} \\
\hline \multicolumn{2}{|c|}{ Milho Płpoca } & A B & 396 & 378 & 3710 & 385 & 365 & $37,46,8$ & 93,5 \\
\hline
\end{tabular}

Tabela 21. Número de adultos de Sitophilus spp. mortos por parcela, em amostras tratadas

(A) e testemunha (B) 330 dias após aplicação..

\begin{tabular}{|l|l|l|l|l|l|}
\hline Grão & Tratam. & Repetições & Média & Mortalidade & Mort. \\
\hline
\end{tabular}

\begin{tabular}{|c|c|c|c|c|c|c|c|c|c|}
\hline & & 1 & 2 & 3 & 4 & 5 & & (\%) & \\
\hline \multicolumn{10}{|c|}{ corrigida } \\
\hline Trigo & A B & 400 & 381 & 320 & 402 & 382 & 37,61 & 942,5 & 94 \\
\hline Milho & $\mathrm{A} \mathrm{B}$ & 345 & 403 & 382 & 353 & 376 & \multicolumn{2}{|c|}{$36,83, \$$} & 92 \\
\hline 9,5 & \multicolumn{9}{|l|}{91} \\
\hline Milho & poca & A B & 386 & 385 & 324 & 407 & 345 & $36,45,4$ & 91 \\
\hline
\end{tabular}

$13,5 \quad 90$ 
Tabela 22. Número de adultos de Sitophilus spp. mortos por parcela, em amostras tratadas (A) e testemunha (B) 360 dias após aplicação..

\begin{tabular}{|l|l|l|l|l|l|}
\hline Grão & Tratam. & Repetições & Média & Mortalidade & Mort. \\
\hline
\end{tabular}

\begin{tabular}{|c|c|c|c|c|c|c|c|c|c|}
\hline & & 1 & 2 & 3 & 4 & 5 & & $(\%)$ & \\
\hline \multicolumn{10}{|c|}{ corrigida } \\
\hline Trigo & A B & 4010 & 402 & 403 & 404 & 400 & 403,8 & 1009,5 & 100 \\
\hline Milho & A B & 302 & 262 & 283 & 341 & 275 & \multicolumn{2}{|c|}{$29,22, \phi$} & 73 \\
\hline 6,5 & \multicolumn{9}{|l|}{71} \\
\hline Milho & poca & $\mathrm{AB}$ & 265 & 300 & 283 & 300 & 322 & 29,22 & 735 \\
\hline
\end{tabular}

72

Pelos dados apresentados nas Tabelas de 10 a 22, observa-se que o inseticida aplicado na dosagem de 12 ppm em grãos de trigo mostrou-se eficiente no controle dos adultos do inseto, durante todo o período em que foram feitas as observações, com ação residual suficiente para causar mortalidade nos indivíduos submetidos à exposição aos grãos tratados, ainda em que pese o fato de que o depósito no tratamento possa ser bem inferior à dosagem pretendida.

Pode-se observar também que, para os grãos de milho e milho pipoca o efeito residual do produto foi menor que para grãos de trigo, de maneira significativa, apenas ao final (no último mês) do período de avaliação (12 meses). 


\section{CONCLUSÕES}

Nas condições experimentais, e com base nos resultados obtidos, pode-se concluir que:

- O método analítico utilizado para as análises de resíduos de pirimifós-metil em grãos de trigo, milho e milho pipoca, bem como em seus produtos processados, mostrou-se adequado, com limites de quantificação de $0,1 \mathrm{mg} \cdot \mathrm{kg}^{-1}$ (ppm) ou inferiores.

- Os resíduos de pirimifós-metil em trigo concentram-se no farelo; as farinhas integral e branca apresentam teores semelhantes aos do grão, e o pão apresenta teores bem abaixo desses.

- Os resíduos de pirimifós-metil em milho concentram-se no farelo, sendo detectados níveis bastante baixos do inseticida na canjica e na farinha.

- Os resíduos de pirimifós-metil em pipoca apresentaram uma pequena redução em relação aos de seus grãos.

- As tolerâncias de pirimifós-metil para grãos armazenados estabelecidas pela legislação brasileira, devem ser reavaliadas para sua melhor adequação.

- O inseticida pirimifós-metil mostrou-se bastante eficiente no controle de Sitophilus spp. em grãos de trigo, milho e milho pipoca. 


\section{REFERÊNCIAS BIBLIOGRÁFICAS}

ALLEONI, B. Resíduos de deltametrina, malation e pirimifós-metil em grãos de milho e sua ação sobre Rhyzopertha dominica (Fabr., 1792) (Coleoptera-Bostrichidae). Piracicaba, 1995. 80p. Tese (Doutorado) - Escola Superior de Agricultura “Luiz de Queiroz”, Universidade de São Paulo.

BAZZI, B.; SANTI, R.; CANALE, G.; RADICE, M. Applications of Cidial (phenthoate) in the control of insect pests of stored products. Metabolism, residues and technological/commercial and hygienic/sanitary implications. Instituto di Ricerche Agrarie, v. 11, p. 27-29, 1972.

BENGSTON, M.; DAVIES, R.A.H.; DESMARCHELIER, J.M.; PHILIPS, M.P.; SIMPSON, B.W. Organophosphorus and synergized synthetic pyrethroid insecticides as grain protectants for stand sorghum. Pesticide Science, v.15, p. 500-508, 1984.

BENGSTON, M.; CONNELL, M.; DAVIES, R.A.H.; DESMARCHELIER, J.M.; PHILLIPS, M.P.; SNELSON, J.T.; STICKA, R. Fenitrothion plus (1R) phenothrin, and pirimiphos-methyl plus carbaryl, as grain protectant combinations for wheat. Pesticide Science, v.11, n.5, p. 471-482, 1980.

BENGSTON, M.; DAVIES, R.A.H.; DESMARCHELIER, J.M.; HENNING, R.; MURRAY, W.J.; SIMPSON, B.W.; SNELSON, J.T.; STICKA, R.; WALLBANK, 
B.E. Organophosphorothioates and synergized synthetic pyrethroids as grain protectants on bulk wheat. Pesticide Science, v.14, n. 4, p. 373-384, 1983.

BITRAN, E.A.; CAMPOS, T.B.; SUPLICY FILHO, N.; CHIBA, S. Avaliação da ação residual de alguns inseticidas na proteção de grãos de milho, trigo e arroz contra pragas de armazenamento. Arquivos do Instituto Biológico, v.58, n.1./2, p. 43-50, 1991.

BROWN, G.L.; PETAGINE, F.; OSBOURNE, B.G.; SEILER, D.A.L. The reduction of chemical and microbial contaminants in wheat. HGCA Project Report, v. 35, p. 1-44, 1991.

CAMPOS, T.B.; BITRAN, E.A.; GEBARA, A.B. Controle de Sitophilus oryzae (L., 1765) (Col. Curculionidae) e Rhyzopertha dominica (Fabr., 1792) (Col. Bostrichidae) em armazém graneleiro. In: CONGRESSO BRASILEIRO DE ENTOMOLOGIA, 13., Recife, 1991. Resumos. Recife: SEB, 1991. p. 459.

COGBURN, R.R. Pirimiphos-methyl as a protectant for stored rough rice: small bin tests. Journal of Economic Entomology, v.69, n3, p. 369-373, 1976.

DAVIES, R.A.H.; DERMARCHELIER, J.M. Combinations of pirimiphos-methyl and carbaryl for stored grain protection. Pesticide Science, v.12, n.6, p. 669-677, 1981.

GABRIEL, E.; SCHIFFERS, B.C.; VERSTRAETEN, C. Use of Rhyzopertha dominica (F.) (Col., Bostrichidae) for the biological dosage of insecticide residues in stored products. Mededelingen van de Faculteit Landbouwwetenschappen, v.54, n.3b, p. 1071-1081, 1989.

GELMINI, G.A.; NOVO, J.P.S. Defensivos agrícolas; informações básicas e legislação. Campinas: Fundação Cargill, 1987. 577p.

HOLLAND, P.T.; HAMILTON, D.J.; OHLIN, B.; SKIDMORE, M.W. Effects of storage 
and processing on pesticide residues in plant products. Pure and Applied Chemistry, v.66, n.2, p. 335-356, 1994.

KORUNIC, Z; HAMEL-KOREN, D. The effect of deltamethrin and pirimiphos-methyl on pests of stored products. Zastita Bilja, v.36, n.4, p. 417-423, 1985.

La HUE, D.W. Pirimiphos-methyl as a short term protectant of grain against stored products insects. Journal of Economic Entomology, v.68, n.2, p. 235-236, 1975.

Le PATOUREL, G. Residues and efficacy of etrinphos, and pirimiphos-methyl in wheat and malting barley stored in ventilated bins. Crop Protection, v.11, n.5, p. 470-476, 1992.

MACIEL, E.; BAPTISTA, G.C.; TUKAMOTO, H.M. Resíduos de fenitrotion em farinha de trigo determinados por cromatografia em fase gasosa. In: CONGRESSO BRASILEIRO DE ENTOMOLOGIA, 14., Piracicaba, 1993. Resumos. Piracicaba: FEALQ, 1993. p.546.

MENSAH, G.W.K.; WATTERS, F.L.; WEBSTER, G.R.B. Insecticide residues in milled fractions of dry tough wheat treated with malathion, bromophos, iodofenphos and pirimiphos-methyl. Journal of Economic Entomology, v.72, p.728-731, 1979.

PAPADOPOULOU, M.; TOMAZOU, T. Persistence and activity of permethrin in stored wheat and its residues in wheat milling fractions. Journal of Stored Products Research, v. 27, n.4, p. 249-254, 1991.

PUCCETI, G.; LUCA D', A.E. DE; COMI, R.; FORTINI, P.; MEATTA, M.; LEONI, V. Health aspects of using pirimiphos-methyl as a preservative for stored grain and presence of organophosphorus pesticide residues in cereal products. Igiene Moderna, v.99, n.2, p. 227-240, 1993. 
REZENDE, A.C.; ISHIZAKI, T.; NOVAES, D.F.; LAZZARINI, S.; MIIKE, H.L. Avaliação prática de K-obiol no tratamento de grãos aramzenados em armazens graneleiros. In: CONGRESSO BRASILEIRO DE ENTOMOLOGIA, 9., Londrina, 1984. Resumos. Londrina: SEB, 1984. p.251.

SAMSON, P.R.; PARKER, R.J. Laboratory studies on protectants for control of Coleoptera in maize. Journal of Stored Products Research, v.25, n.1, p. 49-55, 1989.

SANTOS, J.P.; WAQUIL, J.M. Controle dos principais coleópteros pragas do trigo durante o armazenamento. In: CONGRESSO BRASILEIRO DE ENTOMOLOGIA, 14., Piracicaba, 1993. Resumos. Piracicaba: FEALQ, 1993. p. 534.

SCHROTER, R.A.; GONSALVES, R.; PEREZ, C.A.; NAKANO, O. Ação curativa do Kobiol 25 CE sobre Rhyzopertha dominica (Fabr., 1992) (Col. - Bostrichidae) em grãos de trigo armazenados. In: CONGRESSO BRASILEIRO DE ENTOMOLOGIA, 13., Recife, 1991. Resumos. Recife: SEB, 1991. p. 465.

SOWUNMI, O.E.; FETUGA, B.L. The degradation of pirimiphos-methyl applied to stored yelow maize in the hot humid tropic. Bulletin of grain technology, v.21, n.2, p. 105-109, 1985. /Resumo em Review of Applied Entomology, Ser. A., v. 74, n.2, p. 61, Feb. 1986/

STORRHER, R.W.; OTT, P.; WATTS, R.R. A general method for organophosphorus pesticide residue in nonfatty foods. Journal of the Association of Official Analitical Chemists, v.54, n.3, p.513-516, 1971.

TOMLIN, C. The pesticide manual. 10.ed. London: The Royal Society of Chemistry, 1995. $134 \mathrm{p}$.

TREVIZAN, L.R.P.; Resíduos de deltametrina em grãos de trigo, milho e milho pipoca e em 
seus produtos processados, determinados por cromatografia em fase gasosa. Piracicaba, 1998. 74 p Dissertação (Mestrado) - Escola Superior de Agricultura “Luiz de Queiroz", Universidade de São Paulo. 